\title{
Review Paper \\ The Effect of Social Media Use on Depression in Adolescents: A Systematic Review and Meta-analysis
}

\author{
*Mina Vesal ${ }^{1}\left(\mathbb{C}\right.$, Changiz Rahimi $^{2}$
}

1. Department of Psychology, Faculty of Education and Psychology, Isfahan University, Isfahan, Iran.

2. Department of Clinical Psychology, Faculty of Education and Psychology, Shiraz University, Shiraz, Iran.

\begin{tabular}{|c|c|}
\hline $\begin{array}{l}\text { Use your device to scan } \\
\text { and read the article online }\end{array}$ & Citation: Vesal M, Rahimi Ch. [The Influence of Social Media Use on Depression in Adolescents: A Systematic Review \& \\
\hline 口ifing & $\begin{array}{l}\text { Meta-analysis (Persian)]. Journal of Arak University of Medical Sciences (JAMS). 2021; 24(1):2-23. https://doi.org/10.32598/ } \\
\text { JAMS.24.1.6099.1 }\end{array}$ \\
\hline 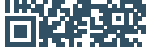 & doi'https://doi.org/10.32598/JAMS.24.1.6099.1 \\
\hline
\end{tabular}

Keywords: Social media, Depression, Adolescence, Systematic review, Meta-analysis

\section{A B STRACT}

Article Info:

Received: 28 Jan 2020

Accepted: 08 Sep 2020 Available Online: 01 April 2021

\section{Extended Abstract}

\section{Introduction}

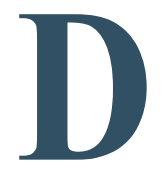

epression is the most prevalent mental health disorder and among the leading causes of death among children and adolescents. This disorder is a major health concern due to its high prevalence, earlyonset, and devastating consequences on children, families, and society [1-3]. Depression is associated with biopsychosocial characteristics; some studies have linked me- dia exposure to the generation of depression in children and adolescents [11]. Using electronic media is common worldwide, especially among children and adolescents [18]. Additionally, global statistics indicate that adolescents use electronic media for about 8 hours a day. Furthermore, evidence suggests that such measures can be a potential risk factor for depression [6]. However, the results of available research are contradictory in this respect. Whether the increase in psychological problems, especially depression in childhood and adolescence, is related to activity on the internet and social networks remains undiscovered.

\section{* Corresponding Author:}

Mina Vesal, PhD.

Address: Department of Psychology, Faculty of Education and Psychology, Isfahan University, Isfahan, Iran.

Tel: +98 (917) 1879378

E-mail: mvesal@edu.ui.ac.ir 


\section{Materials and Methods}

This systematic review and meta-analysis study was conducted based on the Preferred Reporting Items for Systematic reviews and Meta-Analyses (PRISMA) guidelines (2009). To obtain related citations, the appropriate keywords were identified and searched in databases between 2005 and June 2019. Then, with matching articles, overlapping, duplicate, and irrelevant studies were removed. These articles were reviewed and evaluated according to the inclusion criteria and by removing the articles that did not meet the inclusion criteria. Eventually, 15 English articles were included in the research and their results were extracted. Furthermore, the results of 3 Iran-based conference papers were mentioned; however, due to not meeting the eligibility criteria, they were excluded from the meta-analysis.

After performing a systematic review, to analyze the initial research, using CMA software, the effect size was separately calculated per research; the effect size of the fixed effect model and the random effects model, funnel diagram, Q test, and Egger regression method.

\section{Results}

Of the 15 English articles, 10 and 5 were cross-sectional and longitudinal studies, respectively. In total, $10621 \mathrm{sub}-$ jects were surveyed in the articles; of them, approximately $52 \%$ and $48 \%$ were females and males, in sequence, ranging in age from 10 to 18 years.

After performing a systematic review, the information of 15 English articles was entered in CMA-2. The calculated effect sizes presented a distribution from -0.090 to 0.970 ; accordingly, 14 effect sizes were significant and only one effect size related to the research of Selfoot et al. (2009) was not significant (Figure 1). To determine the meta-analysis model, the homogeneity of the studies was assessed using the $\mathrm{Q}$ test (Table 1).

The obtained data indicated that the average effect of social networks (random-effects model) on depression was equal to 0.18 in the sample. The estimated effect size was significant; therefore, there was a significant correlation between social network use and depression in the explored children and adolescents. Based on Cohen's interpretive criteria, the collected effect size (0.18) was low.

Moreover, the studies included in this meta-analysis applied cross-sectional and longitudinal research design which might have attributed to the data heterogeneity. Therefore, the effect sizes are separately listed concerning the research design in Table 2.

As per Table 2, the effect size of longitudinal and crosssectional research was medium (0.47) and low (0.17), respectively. However, for more accurate inferences, further longitudinal research is required. In other words, social network use, in longitudinal studies, moderately influenced depression, while this effect was small in cross-sectional studies.

\section{Discussion and Conclusion}

This article examined the impact of social media use on depression by reviewing the relevant research in adolescents in the last 15 years (2005 to June 2019). The present research results indicated the effect of social network use on depression (this effect was small but significant).

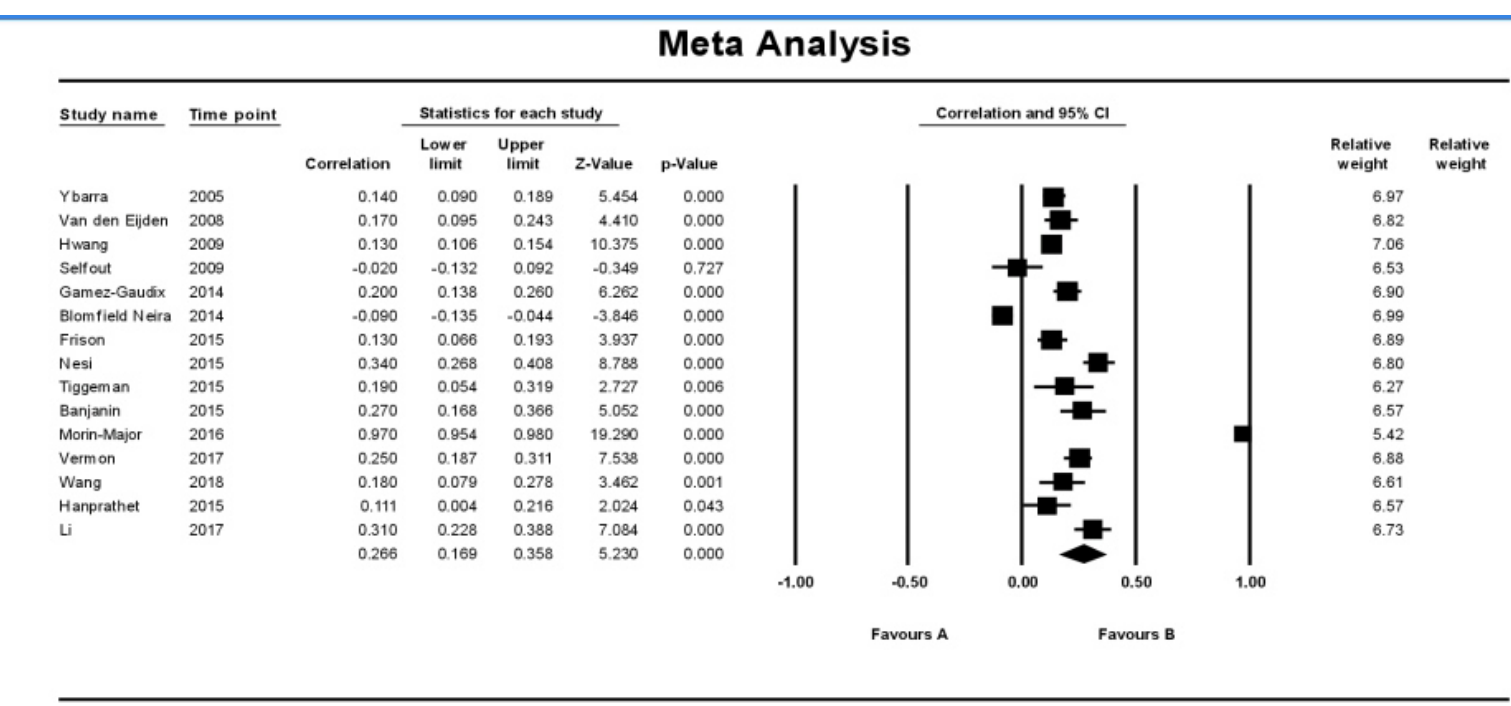

Meta Analysis

Figure 1. Forest plot 
Table 1. Q test results

\begin{tabular}{cccc}
\hline Q Test Value & df & P & I-square \\
\hline 495.951 & 14 & 0.000 & 97.177 \\
\hline
\end{tabular}

Table 2. The effect size of studies by research design

\begin{tabular}{cccccccccccccc}
\hline & & \multicolumn{4}{c}{ Random Effects Model } & \multicolumn{5}{c}{ Fixed Effect Model } \\
\cline { 3 - 13 } Research Design & No. of Studies & & Effect Size & Min. & Max. & Z & P & $\begin{array}{c}\text { Effect } \\
\text { Size }\end{array}$ & Min. & Max. & Z & P \\
\hline Cross-section & 10 & 0.170 & 0.091 & 0.246 & 4.181 & 0.000 & 0.124 & 0.107 & 0.141 & 1.094 & 0.000 \\
Longitudinal & 5 & 0.479 & 0.178 & 0.698 & 2.989 & 0.003 & 0.239 & 0.204 & 0.273 & 1.073 & 0.000 \\
\hline
\end{tabular}

In this study, of 15 articles, 5 were conducted longitudinally. These articles examined a short time, with 12 months as the longest interval between assessments. Due to the widespread use of social networks, there is no control group naturally, which complicates the analysis of longitudinal data. Furthermore, based on evidence from cross-sectional research (10 studies), it is impossible to conclude whether the use of social media causes depression and other mental health issues, or whether depressed individuals spend more time in such platforms, generate addictive and problematic behaviors and invest in the social media.

Additionally, certain attitudes or behaviors, such as social comparison and motives for using social media, may provide a greater impact on depressive symptoms than the number of times social media is used or the number of virtual friends; further research is suggested in this respect.

Overall, this systematic and meta-analysis review revealed the overall impact of social media use on depression. This is a simple expression of a complex relationship; limited research has examined the effect of moderating or mediating variables. Therefore, mediator and moderator variables should be examined. Most of the studies were cross-sectional; thus, a causal relationship between social media use and depression cannot be inferred. Given that research conducted in Iran has only examined internet addiction, future research is necessary in this area.

\section{Ethical Considerations}

\section{Compliance with ethical guidelines}

This article is a meta-analysis without any human or animal sample.

\section{Funding}

This research did not receive any grant from funding agencies in the public, commercial, or non-profit sectors.

\section{Authors' contributions}

Conceptualization, methodology, and analysis: Mina Vesal; Data collection, extracting findings, writing drafts, editing, and finalizing: Both authors.

\section{Conflicts of interest}

The authors declared no conflicts of interest. 


\title{
مقاله مرورى
}

ثأثير استفاده از رسائهاى اجتماعى بر أفردكى در ثوجوانان: مرور ثظاممند و فراتثليل

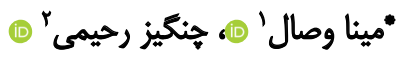

ا. كروه روانشناسى، دانشكده علوم تربيتى و روانشناسى، دانشكاه اصفهان، اصفهان، ايران.

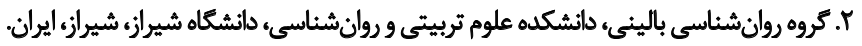

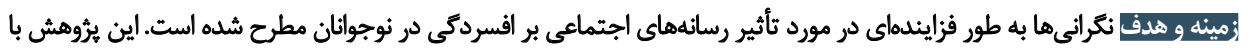

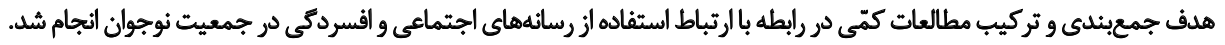

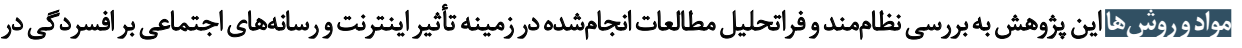

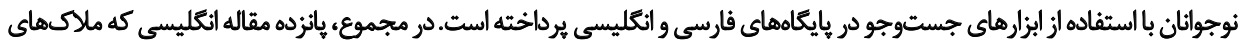

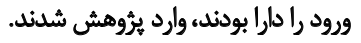

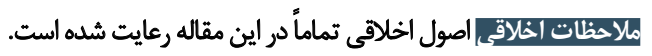

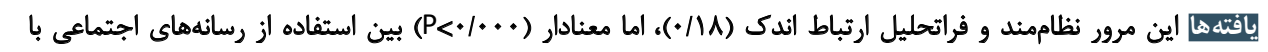

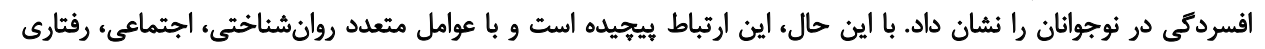

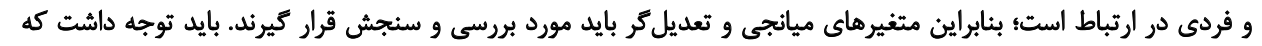

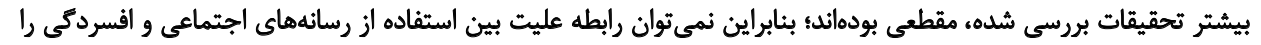

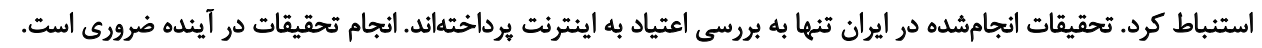

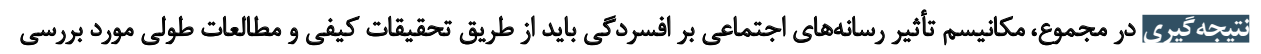

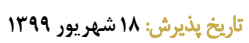

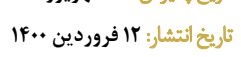

كليدواروها:

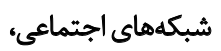

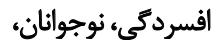

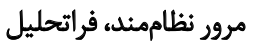

همجنين افسردخى با رفتارهاى مخرب سلامت مانند جاقى،

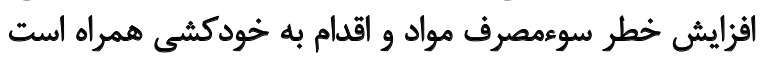

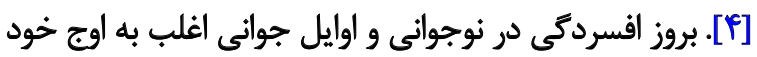

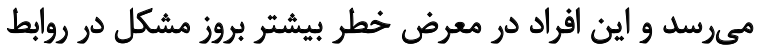

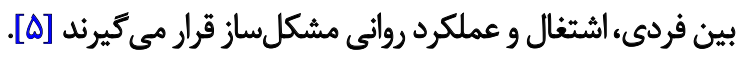

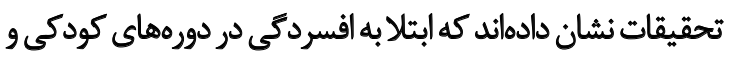

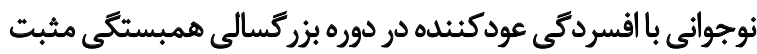

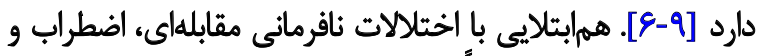

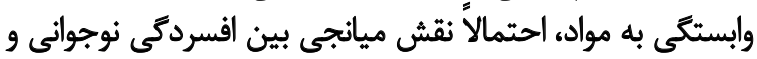

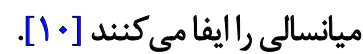

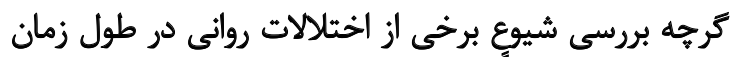

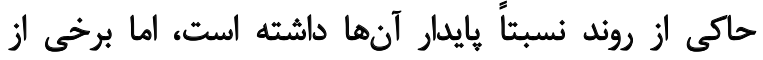
اختلالات همجون افسردگى در نوجوانان افزايش داشته است. doles

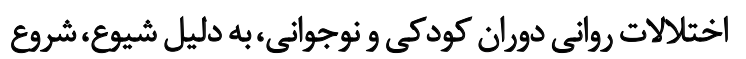

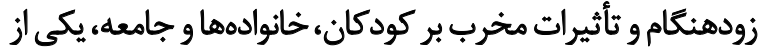

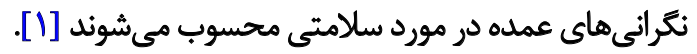

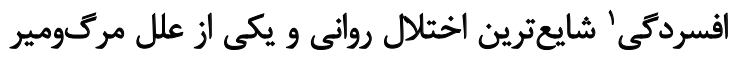

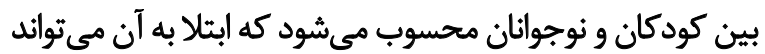

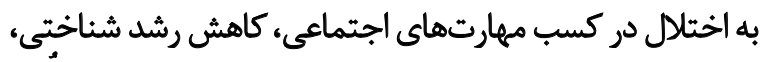

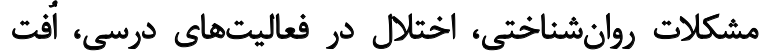

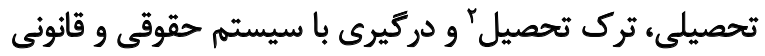

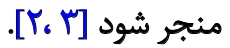

1. Depression

2. School Dropout

: نويسئده مسئول:

دكتر مينا وصال

نشائي: اصفهان، دانشكاه اصفهان، دانشكده علوم تربيتى وروانشئاسى، كروه روانشئاسى.

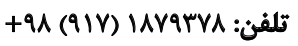
mvesal@edu.ui.ac.ir :بعت الكترونيكي 


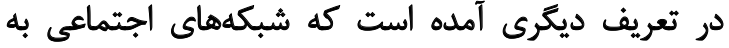

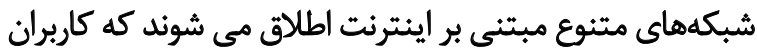

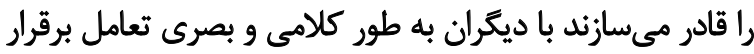

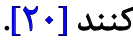

رسانههاى اجتماعى امكانات متنوعى را به منظور تأمين اهداف

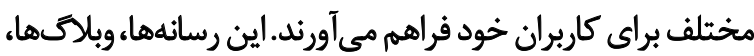

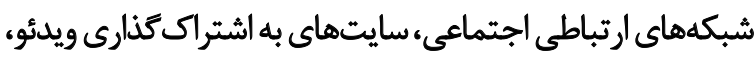

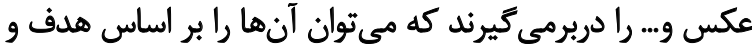

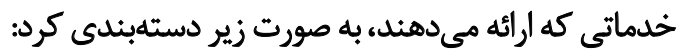
- شبكهاي اجتماعى (فيسبوك، ماى اسيس، كوگل بيلاس

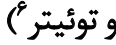

- شبكههاى اجتماعى حرفهاى (لينكدان")

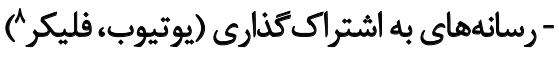
- رسانهاي توليد محتوا (بلاكر، توئيترج)

- رسانههاي كردآورنده دانش / اطلاعات (ويكى بديا.')

- واقعيت مجازى و محيط بازى (سكند لايف") [ [T]" رسانههاى ارتباطى اجتماعى مانيد فيسبوكى، اينستاكرام و وزئ

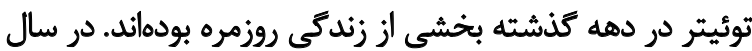

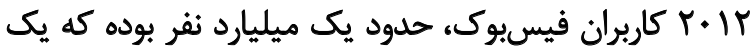

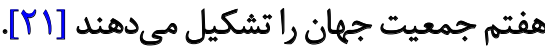

به كَارش استاثيستاّا' (شركتى تحقيقاتى در حوزه بازاريابى)

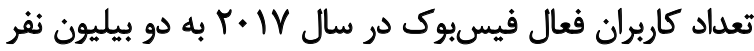

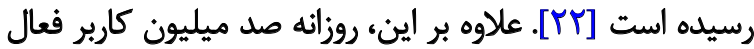

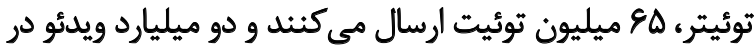

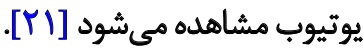

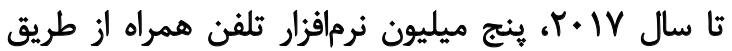

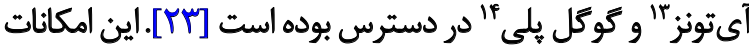

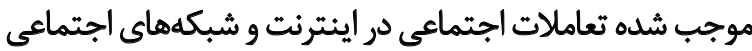

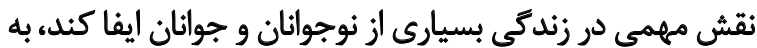

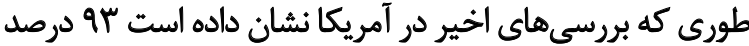

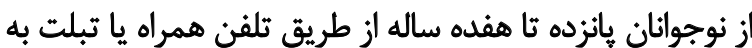

6. Facebook, MySpace, Google Plus, Twitter

7. Linkedin

8. YouTube, Flickr

9. Blogger, Twitter

10. Wikipedia

11. Second Life

12. Statista

13. I Tunes

14. Google Play
شيوع اختلالات روانى در اين دوره سنى حاكى از ضرورت

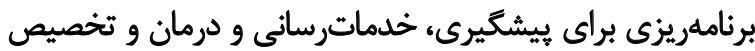
بودجه لازم است.

اختلالات روانى بيشترين بخش هزينههاى درمانى (N/ بيليون

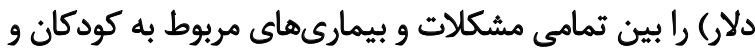
نوجوانان، به خود اختصاص داده است [1]

افسردكى با تركيبى از عوامل بيولوزيكى، روانشناختى و وانو

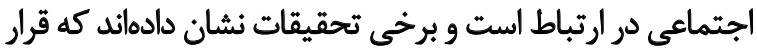

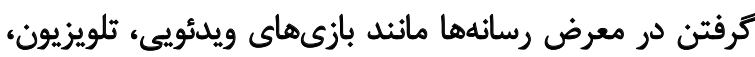

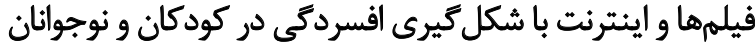

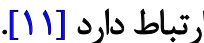

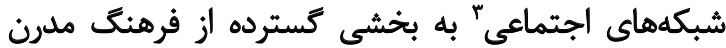

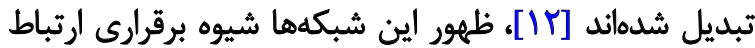

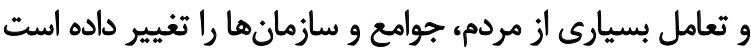

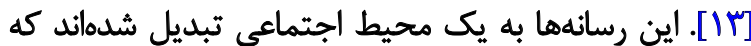

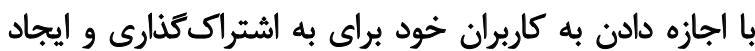

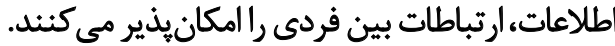

در سراسر دنيا مردم از اينترنت و رسانهها به عنوان وسيلهاي

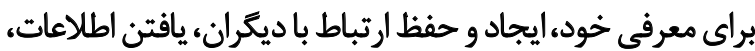

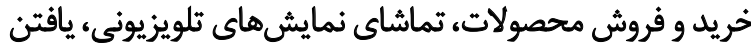

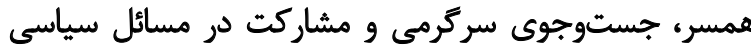

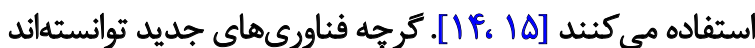

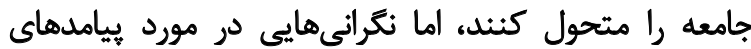

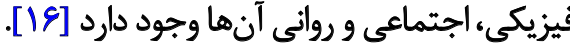
استفاده از رسانههاي اجتماعى در سراسر جهان، بلويرَه در

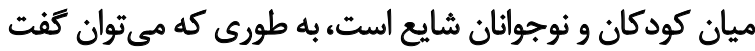

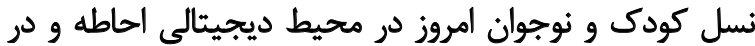

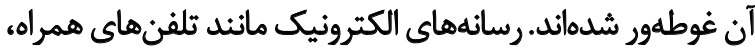

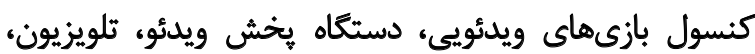

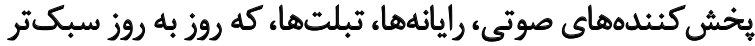

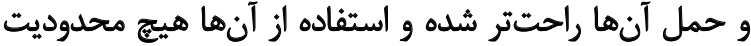

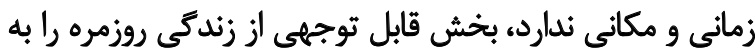

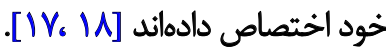

تعريف "رسانههاى اجتماعى "ه، مدام در حال تحول است. به إنه

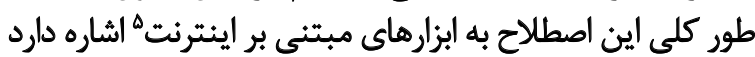

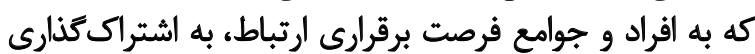

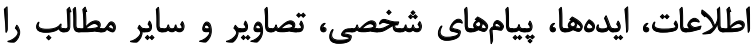

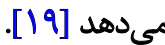

3. Social Networking Sites (SNS)

4. Social Media

5. Internet-based Tools 


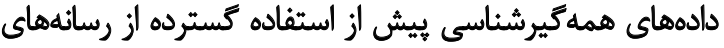

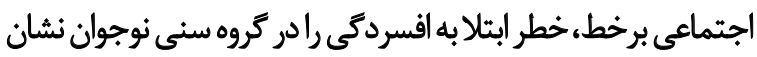

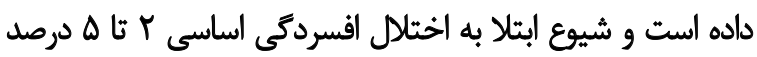

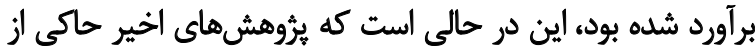

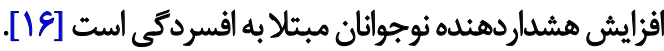
دركى تأثير رسانههاى اجتماعى روى بهزيستى و سلامت روان

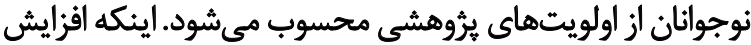

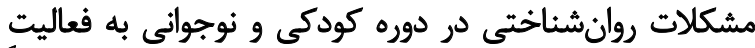

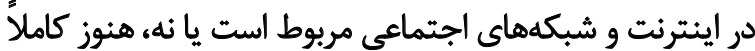
مشخص نشده است.

مطالعات بسيارى در خصوص ارتباط بين افسردكى و استفاده

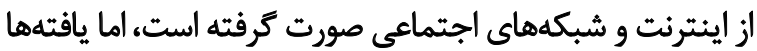

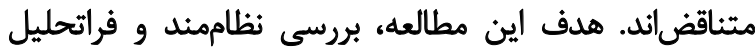

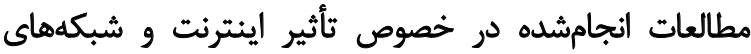

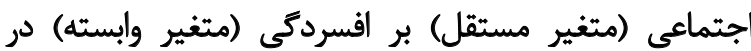

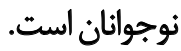

\section{مواد و روشها}

اين مطالعه با روش مرور نظاممند و فراتحليل انجام شده است.

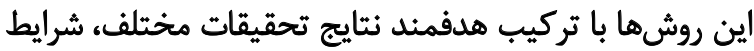

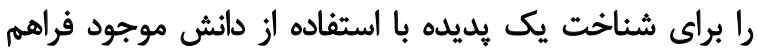

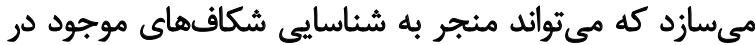

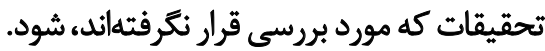

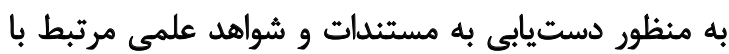

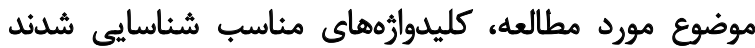

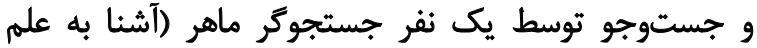
كتابدارى)، به انكليسى با استفاده از كليدوارههاى, depression depressive symptoms, depressed mood, social media, internet, social network, Facebook, Twitter, adolescent در بايكاههاى اطلاعاتى امبيس"، مدلاين" PsychINFO, Cumulative Index to Nursing and Allied Health (CINAHL), Social Sciences Citation Index (انجام شد. (SSCl) Science Direct

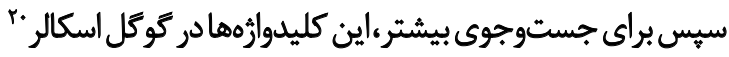

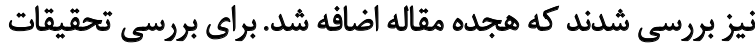

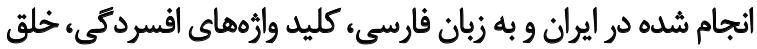

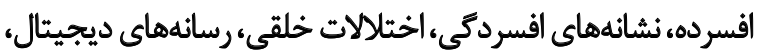

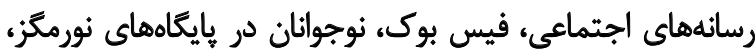

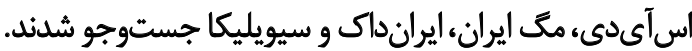

18. Embase

19. Medline

20. Google scholar

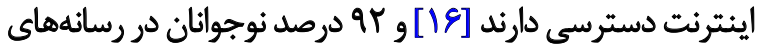

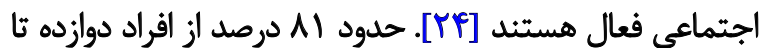

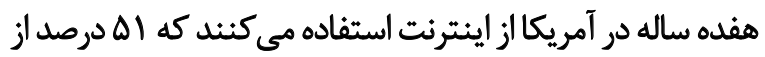

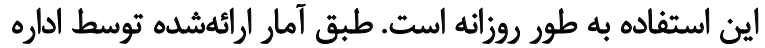

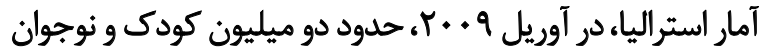

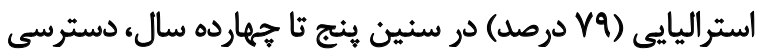

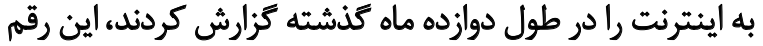

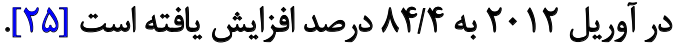

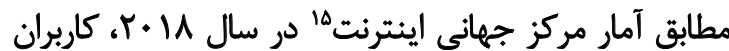

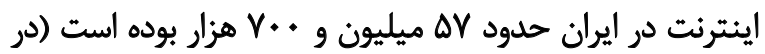

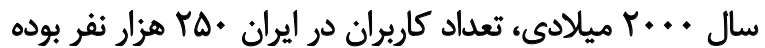

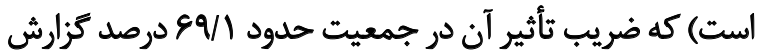

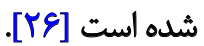

هرجند آمار دقيقى درخصوص تعداد و ميزان استفاده كودكان

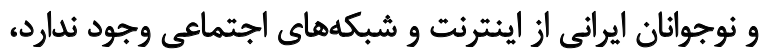

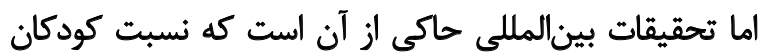

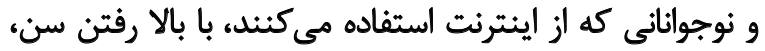

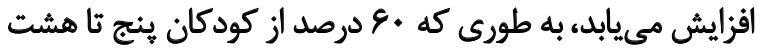

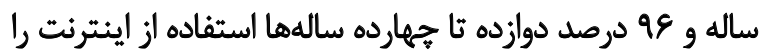

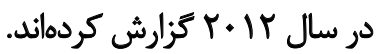

آمارها در آمريكا نشان مى دهد كه بيش از •و درصد نوجوانان

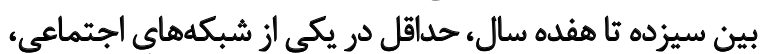

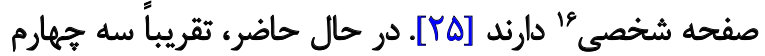

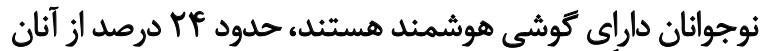

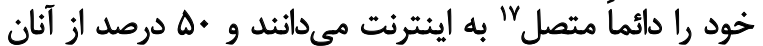

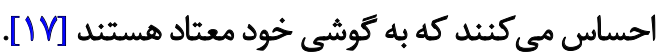

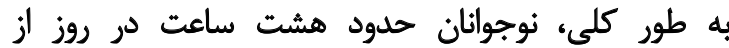

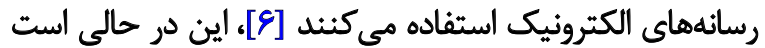

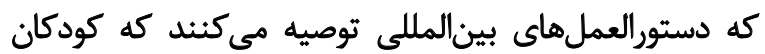

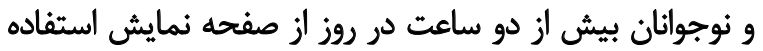

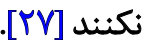

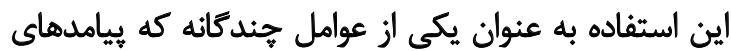

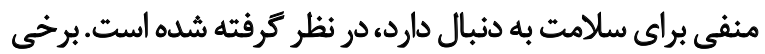

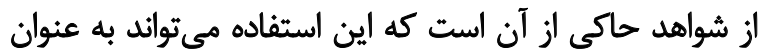

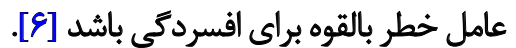

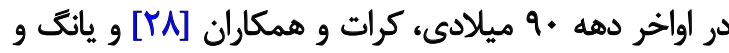

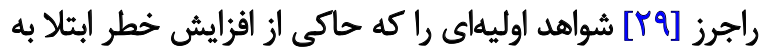

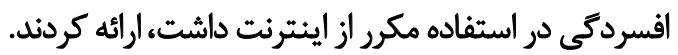

15. Internet World Stats

16. Profile

17. Constantly Connected 
جدول ا. معيارهاى ورود و خروج مقالات به ئروهش

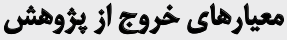

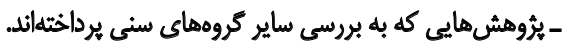

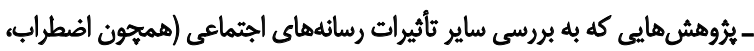

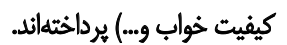

- ئروهش هائى غير از زبان هاى فارسى و ائكليسى

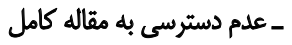

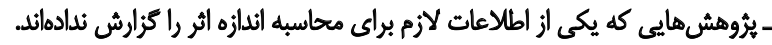

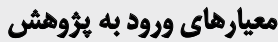

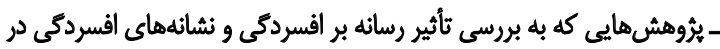

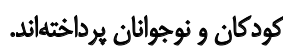

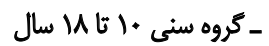

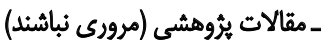

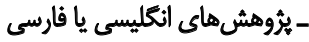

\section{batol}

از مجموع يانزده مقاله، ده مقاله انكليسي به صورت مقطعى

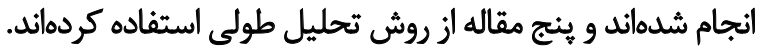

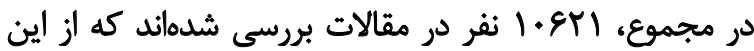

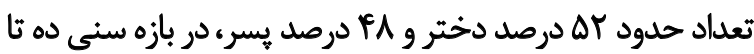

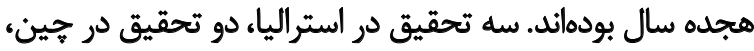

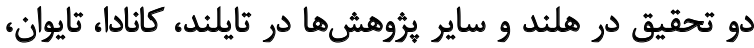
بلزيك آمريكا و صربستان انجام شدهاند.

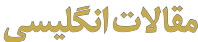

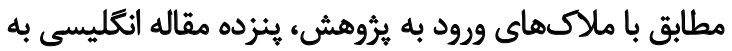
اين يثوهش وارد شدئد.

$$
\text { : }
$$

از اين تعداد، ده مقاله به صورت مقطعى انجام شدهاند كه در

$$
\text { ذيل به نتايج آنان اشاره مي دشود: }
$$

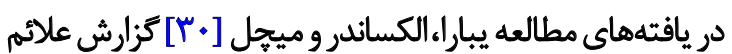
افسردكى با استفاده از اينترنت و يا جنسيت ارثباطي ندارئ نداشت

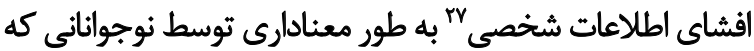

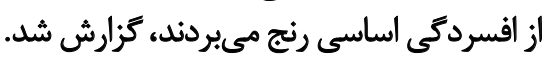

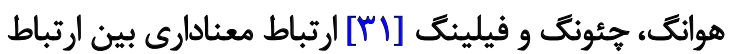
برخط و خلق افسرده هيدا كردند. اين مطالعه نشان داد كاد كه

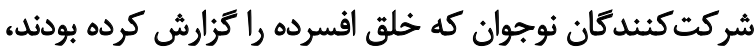

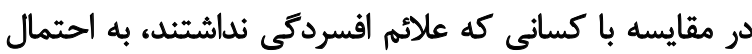

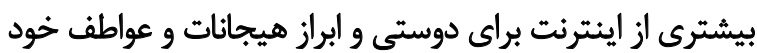

$$
\text { استفاده مي كردند. }
$$

اين محققان نشان دادند كه نوجوانان افسرده در ياقتن دوست

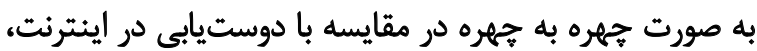

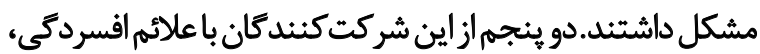

همجنين، بخش منابع مقالات مورد بررسي قرار كرفت و يك مانك

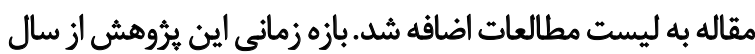

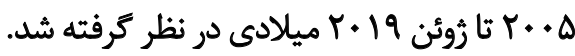
سيس دو يرُوهشَّر به صورت مستقل، عناوين مقالات بازيابي

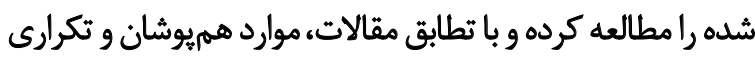

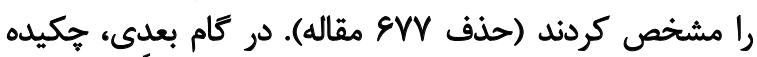
مقالات بررسى و موارد غيرمرتبط حذف شيدند. نهايتاً اين مقالات با توجه به معيارهاى ورود، مورد بررسى و سنجش موردئ قرار كرفتند. معيارهاي ورود و خروج در جدول شماره ا نشان داده شده

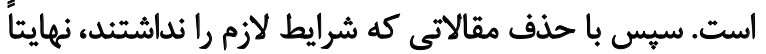

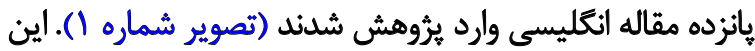

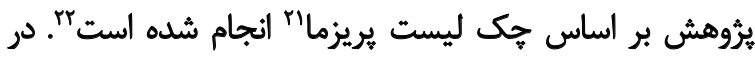

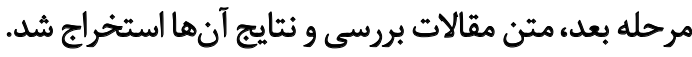

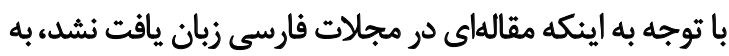

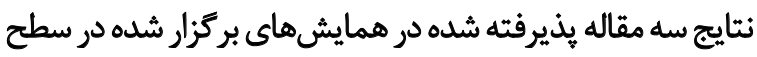

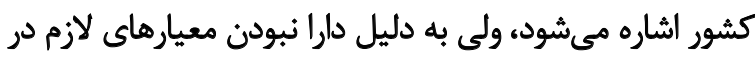

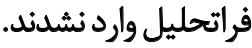

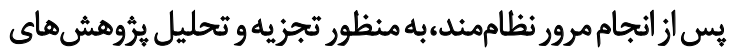

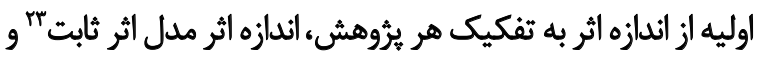

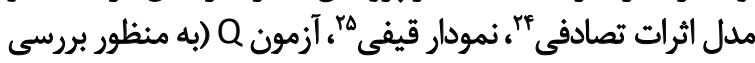

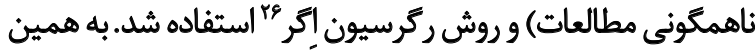

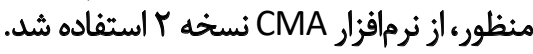

\section{PRISMA Checklist 2009}

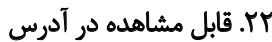
http://prisma-statement.org/PRISMAStatement/Checklist.aspx 23. Fixed Effect Model

24. Random Effects Model

25. Funnel Plot

26. Egger Regression 


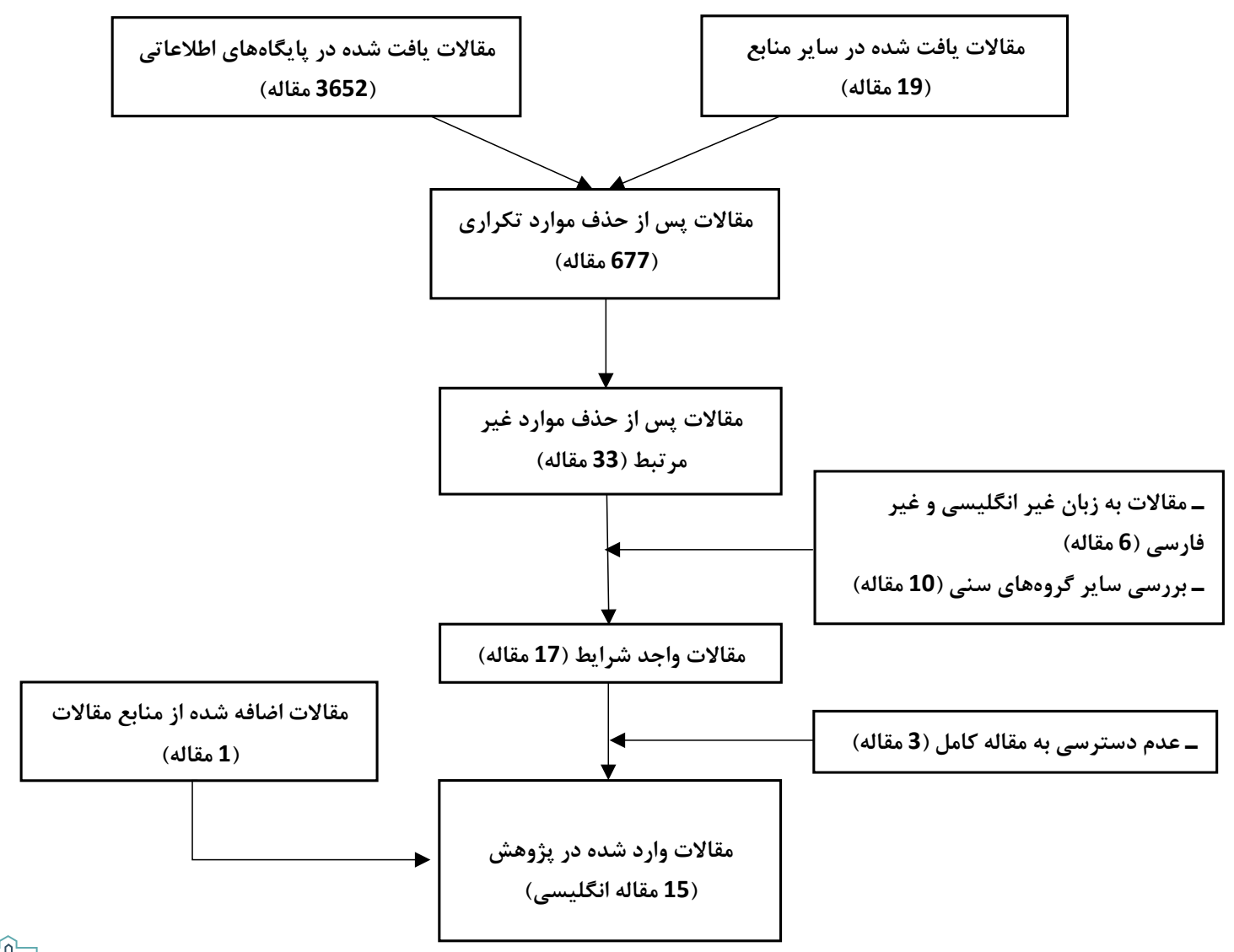

همجنين ارتباطى بين فعاليت در شبكههاى اجتماعى و افسردمى مشاهله نشل.

استفاده فعال يا منفعلانه از فيسبوكى در بررسى فريسون و

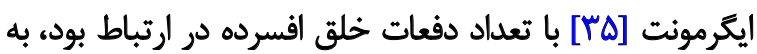

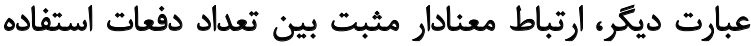

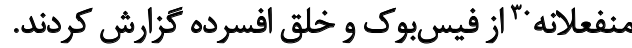

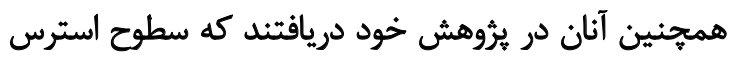

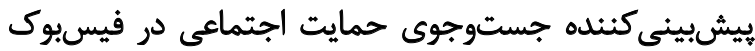

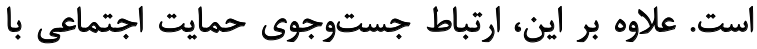

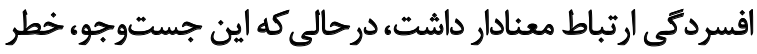

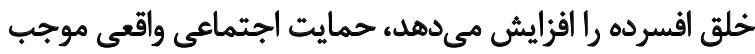
كاهش آن ميى آسرده.

در مطالعه روى مقايسه اجتماعى" "م جستوجوى بازخورد

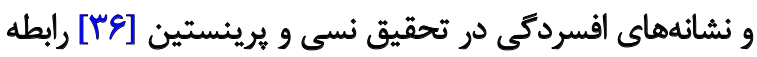

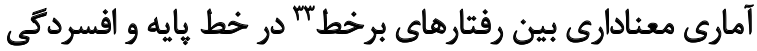

\section{Passive Use}

31. Social Comparison

32. Feedback-seeking

33. Online Behaviors
تصوير ا. فرايند جستوجو و انتخاب مقالات بر اساس نمودار يريزما (PRISMA)

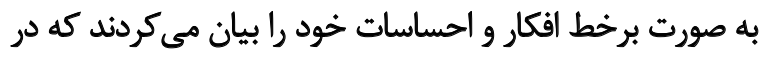
غير اين صورت نمى توانستند اين كار را انجام دهند.

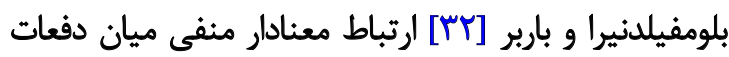

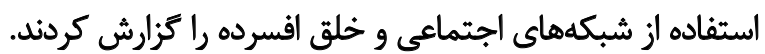

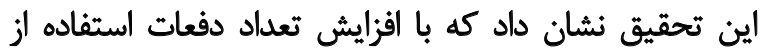

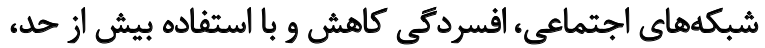

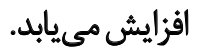
همجنين در اين تحقيق مشخص شد كه بين سرمايهُّذارى در

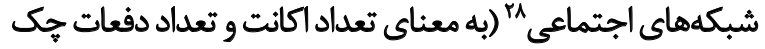
كردن ييامها) و خلق افسرده ارتباط معنادار وجود دارد. نتايج تحقيق تيكمن و اسلاتر [بس] حاكى از ارتباط معنادار

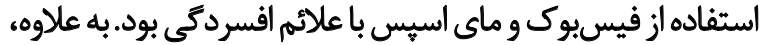

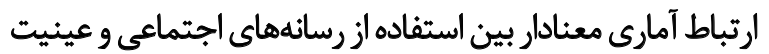

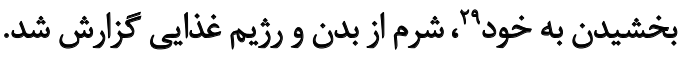

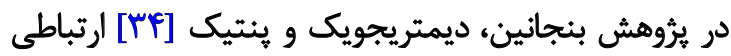
بين تعداد دفعات استفاده از شبكههاي اجتماعى و خلقي افسرده و

28. Social Media Investment

29. Self-objectification 
علائم افسردخى در طى سه هفته در برؤهش مورين مازور، مارين،

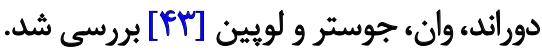

نتايج آن نشان داد كه سطح كورتيزول به طور مثبت با تعداد

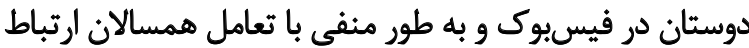

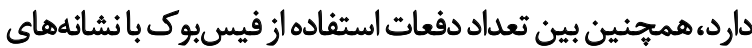
افسردكى ارتباط منفى مشاهده شد، ولى اين رابطه ازئن نظر آماري

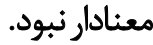

در بررسى طولى ورنون، موداكى و باربر [Ff] ارتباط بين

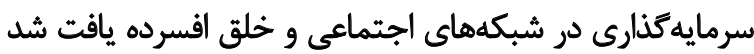

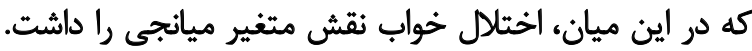
خلاصه مقالات انغليسى در جدول شماره ب آمده است.

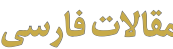

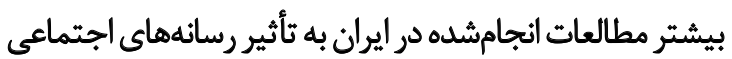

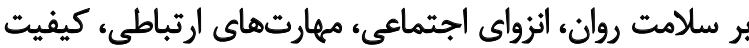

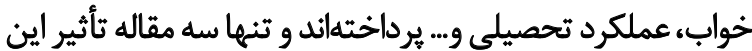

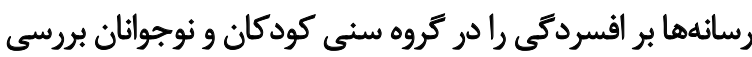

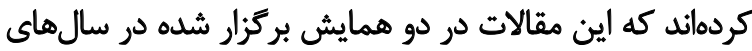
ا

نمونه كيرى اين سه مقاله در استانهاى آذربايجان شرقى (شهر

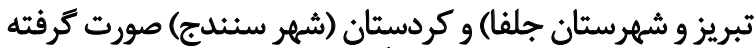

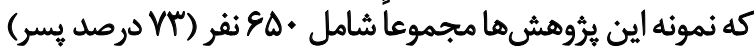

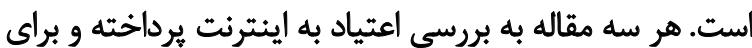

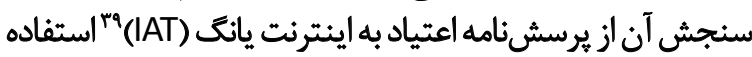

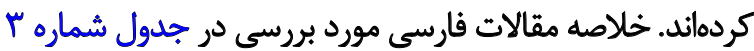

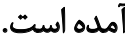

آذرنيياد، شريفى، مدنى و خانبانى [\&ه] با بررسى دويست

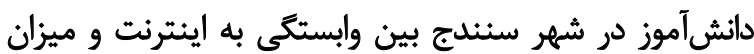

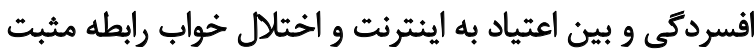

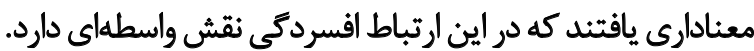

در تحليل رگرسيون انجامشده در يُروهش بيرانوند و عزيزى دري

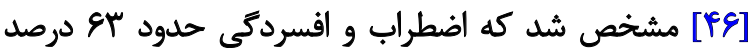

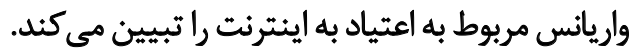

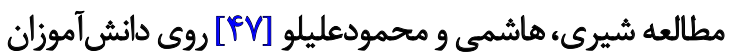

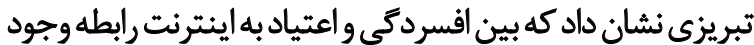

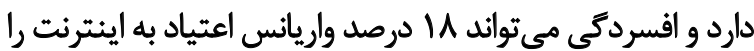

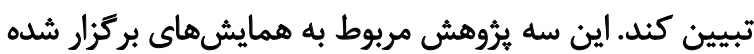

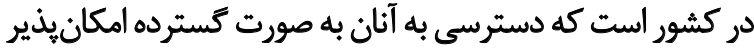

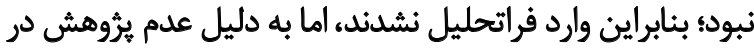

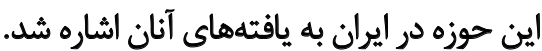

39. Internet Addiction Test (IAT)
در دوازده ماه بعد مشاهده شد. همجنين اين يُروهشكُران دريافتند

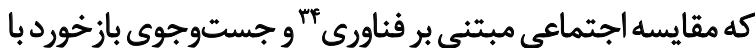
نشانههاى افسردگیى در ارتباط است.

سه يُووهش مقطعى به اعتياد به اينترنت و رفتارهاى مرتبط با

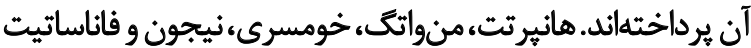

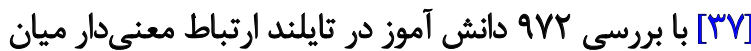

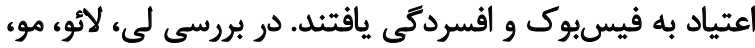

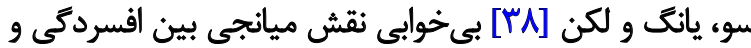

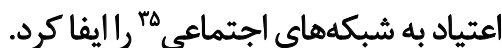

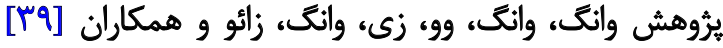

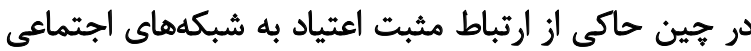

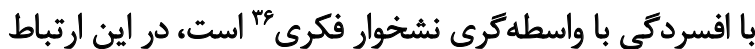

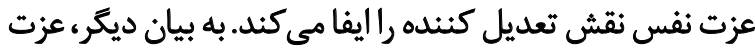

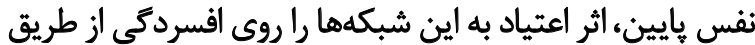
نشخوار فكرى تقويت مى كند. ت نقين.

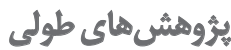

شش يروهش از روش تحقيق طولى استفاده كردهاند كه در ادامه به نتايج آنها اشاره مي رشود:

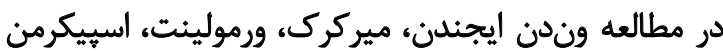

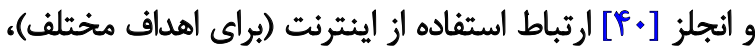

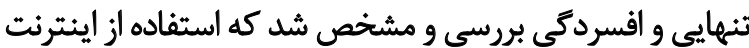

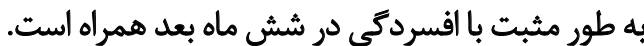

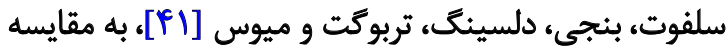

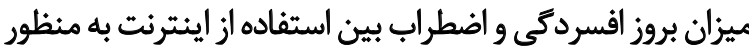

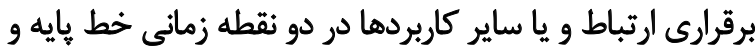
دوازده ماه بعد يرداختند.

نتايج نشان داد كه بين ييامهاى اينترنتى و افسردكى يس از

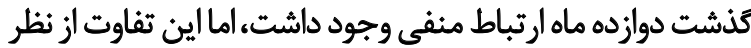

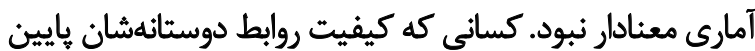

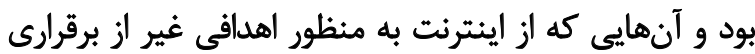

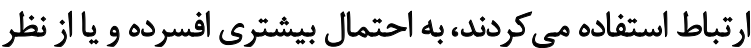

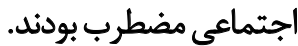

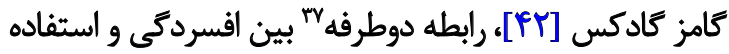

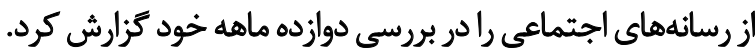
ارتباط بين سطح كورتيزول ^" إيه، فعاليت در فيسبوك و

34. Technology-based Social Comparison

35. Social Media Addiction

36. Rumination

37. Bidirectional Relationship

38. Cortisol 
جدول r. خلاصه يافتههاي مطالعات انجامشده در خارج از كشور در زميئه تأثير رسائهها بر افسردكى كودكان و نوجوانان

\begin{tabular}{|c|c|c|c|c|c|c|c|c|c|}
\hline \multirow{2}{*}{ البزار سنجشي افئى } & \multirow{2}{*}{ متغيرهاي مورد بررسى } & \multicolumn{2}{|c|}{ جنسيث (درصد) } & \multirow{2}{*}{ حجم نمونه } & \multirow[b]{2}{*}{ سن } & \multirow{2}{*}{ موش موالعd } & \multirow{2}{*}{ يُؤهلش محل } & \multirow{2}{*}{ نويسندكان و انتشار } & \multirow{2}{*}{ رديف } \\
\hline & & يسر & ختر & & & & & & \\
\hline لهُ نشانه از DSM & ارتباطاته اينترنتى برخطاى افسردى & درصد & مرصد & |-10 انفر & 1V - IV سال & مقطعى & أمريكا & 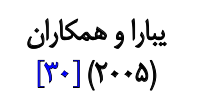 & 1 \\
\hline جى ليست خلق أفردا & افسردكى و تنتهاييى الرتباتي، & 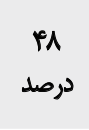 & مرصد & 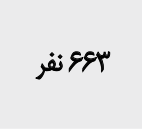 & 10 - Iי سال & تحليل & هاهند & 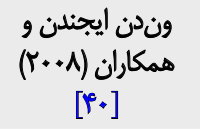 & r \\
\hline مقياس خُودآزّمايى خلق & فعاليتهاي برخط، خلق & $\begin{array}{l}\text { Pوصد } \\
\text { Pq }\end{array}$ & مرصد & | & & مقطعى & ثايوان & $\begin{array}{c}\text { هوانك و همكاران } \\
{[r+9)(r+9)}\end{array}$ & $r$ \\
\hline مقياس افسردكّى & 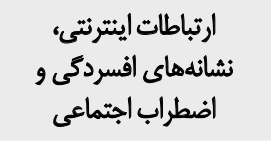 & $\begin{array}{l}p q \\
\text { gوصد }\end{array}$ & $\begin{array}{l}\text { D) } \\
\text { Dوصد }\end{array}$ & Y & IV IV IV & تحليل & هالند & 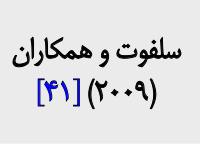 & $f$ \\
\hline 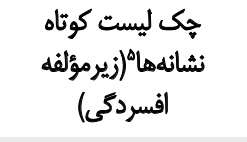 & 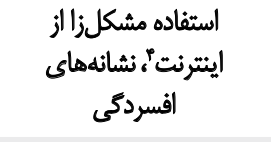 & دوصد & $\begin{array}{l}\text { S } \\
\text { دوصد }\end{array}$ & 9 9 نفر & IV - Iا سال & طتوليل & اسيانيا & 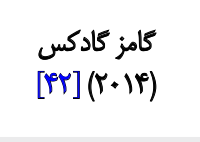 & $\Delta$ \\
\hline مقياس خلق افسردهء & 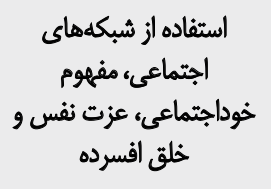 & Pرصد & مرصد & انفر M19 & IV - IV سال & مقطعى & استراليا & 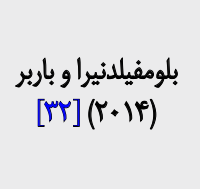 & 8 \\
\hline 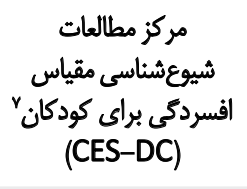 & 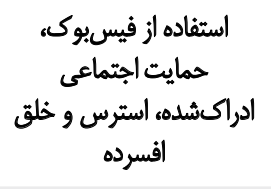 & درصد & مرصد & 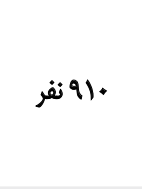 & دوره متوسطة & مقطعى & بلزيك & 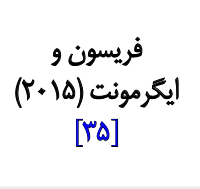 & $\checkmark$ \\
\hline احساسات فوثاه خلق و & 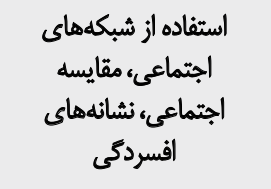 & درصد & 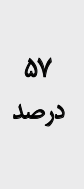 & ا8 & عا -r| سال & مقطعى & أمريكا & نسى و يرينستين & $\Lambda$ \\
\hline كودكان (فرم كوثاه) & 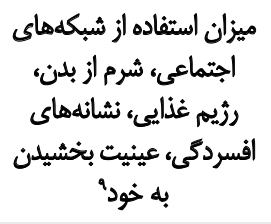 & - & ل & 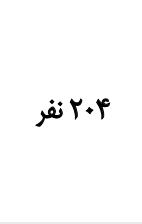 & ri - - (سال & مقطعى & استراليا & 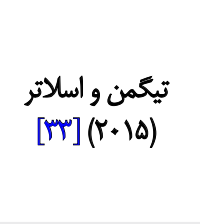 & $q$ \\
\hline عمومى "يرست (GHQ سلامت & 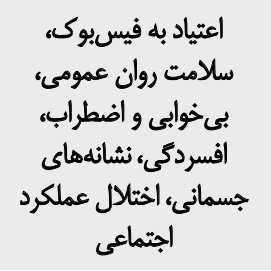 & $\%$ rA & $\% \& r$ & 9 ن نفر & دوره متوسطه & همطعى & تايليند & 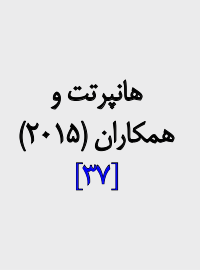 & 1. \\
\hline 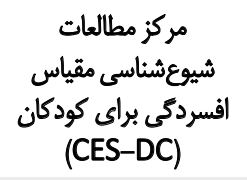 & 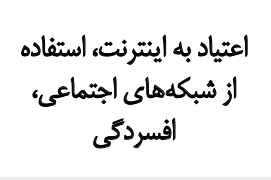 & درصد & مرصد & ع ع ع نفر & دوره متوسطله & مقطعى & صربستان & 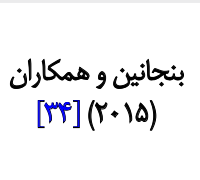 & 11 \\
\hline مقياس افسردكى & 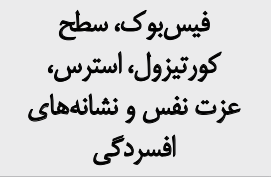 & $\begin{array}{l}\text { PV } \\
\text { Sog }\end{array}$ & مر & M نفر M & IV- IV IVال IV & تحليل تحلى & كانادا & 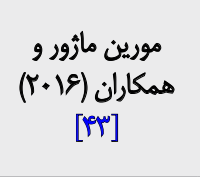 & ir \\
\hline
\end{tabular}




\begin{tabular}{|c|c|c|c|c|c|c|c|c|c|}
\hline \multirow{2}{*}{ القسردئى سنش } & \multirow{2}{*}{ متغيرهاى مورد بررسى } & \multicolumn{2}{|c|}{ جنسيت (درصد) } & \multirow{2}{*}{ حجم نمونه } & \multirow{2}{*}{ سن } & \multirow{2}{*}{ مطالعه } & \multirow{2}{*}{ يثوهشل } & \multirow{2}{*}{ سويسندال انتشان و } & \multirow{2}{*}{ رديف } \\
\hline & & يسر & دختر & & & & & & \\
\hline 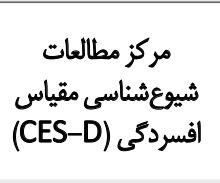 & 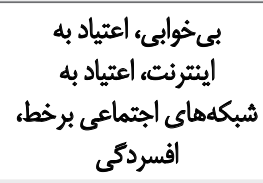 & $\begin{array}{l}\Delta q \\
\text { درصد }\end{array}$ & $\begin{array}{l}\text { درصد } \\
\text { د }\end{array}$ & ه1هان انفر & كالاس هفتم & مقطعى & جين & 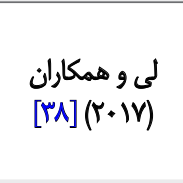 & r \\
\hline مقياس خلق افسرده & 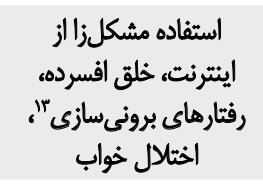 & $\begin{array}{l}P 1 \\
\text { درصد }\end{array}$ & دوصد & An نقر An & كلاس نهم تاز & تحليل & استراليا & 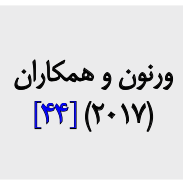 & if \\
\hline 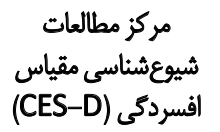 & 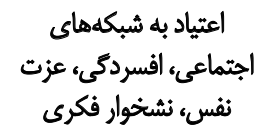 & $\begin{array}{l}\text { درصد } \\
\text { در }\end{array}$ & $\begin{array}{l}\Delta r \\
\text { دصد }\end{array}$ & ل هوب نقر & & هقطعى & هين & وانك و همكاران & 10 \\
\hline
\end{tabular}

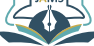

1. The Depressive Mood List

2. Adolescent Depressive Mood Self-Detecting Scale (ADMSS)

3. Children's Depression Inventory (CDI)

4. Problematic Internet Use

5. Brief Symptom Inventory (BSI)

6. The Depressed Mood Scale

نسى و يرينستين [عץ] بين مقايسه اجتماعى و جستوجوى كرئ

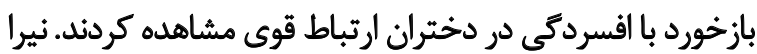

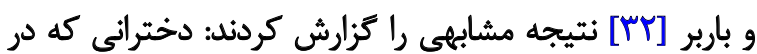

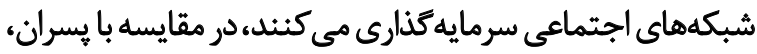

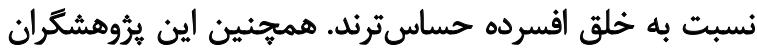

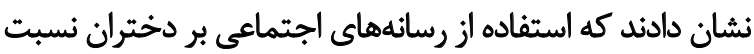

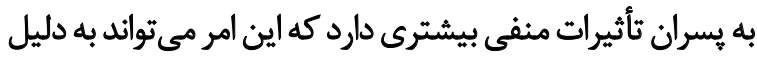

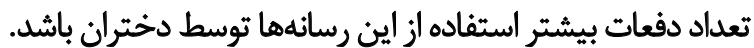

7. The Center for Epidemiological Studies Depression Scale for Children (CES-DC)

8. The Short Mood and Feelings Questionnaire (SMFQ)

9. Self-objectification

10. The Short Form of the Children's' Depression Inventory

11. The General Health Questionnaire (GHQ)

12. The Child Depression Inventory (CDI)

13. Externalizing Behavior

ing , thic

در برخى از مقالات مورد بررسى به نقش جنسيت، به دليل تفاوت

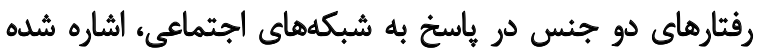

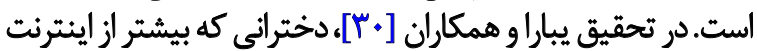

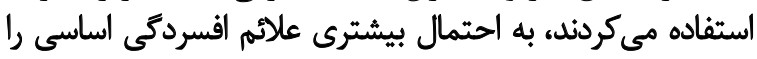

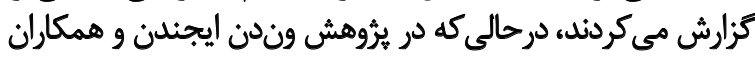

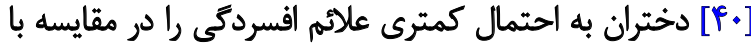

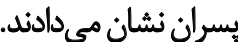

جدول ץ. خلاصه يافتههاى مطالعات انجامشده در ايران در زمينه تأثير رسانهها بر أفردكى كودكان و نوجوانان

\begin{tabular}{|c|c|c|c|c|c|c|c|c|c|}
\hline \multirow{2}{*}{ ابزار سنجش افسردكى } & \multirow{2}{*}{ متغيرهاى مورد } & \multicolumn{2}{|c|}{ جنسيت (دوصد) } & \multirow{2}{*}{ مجيم نمونه } & \multirow{2}{*}{ سن } & \multirow{2}{*}{ 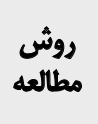 } & \multirow{2}{*}{ ليؤش مجل } & \multirow{2}{*}{ نويسندكان و انتشار } & \multirow{2}{*}{ رديف } \\
\hline & & | - كسر & دختر & & & & & & \\
\hline $\begin{array}{l}\text { مقياس افسرد5ى بكى } \\
\text { (BDI) }\end{array}$ & 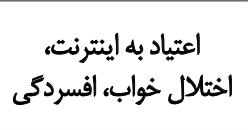 & درصد & . & | & دوره مثوسطه & & سنندج & 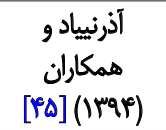 & 1 \\
\hline اضطراب بيمارستانى' & اضطراب، افسردكى ايتثن، & درصد & • ه درصد & . ها نفر. & دوره متوسطه & & شهرستان & 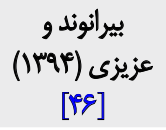 & $r$ \\
\hline $\begin{array}{c}\text { مقياس افسردكى بك } \\
\text { (BDI-II) }\end{array}$ & أفسردمى & لر & - & 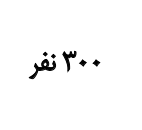 & سال جيهارم & 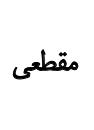 & تببيز & 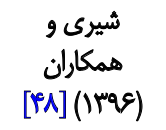 & $r$ \\
\hline
\end{tabular}

Hospital Anxiety \& Depression Scale .1 
جدول f. خلاصه مقالات كزينش

\begin{tabular}{|c|c|c|c|c|c|c|c|c|c|}
\hline 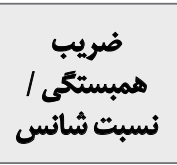 & همبستكى & نمونه & نويسندكان & رديف & |مبستئي & همبستئكى & نمونه & نويسندكان و انتشار & رديف \\
\hline$r=* / r^{r}$ & فيس جمايت الجتماعى درى اخلق & . نو & 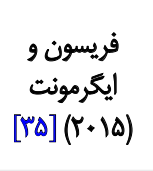 & $v$ & $r=. / 1 f$ & 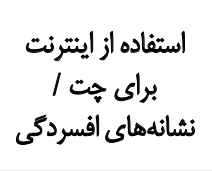 & |a النقر & يباراو همكاران & 1 \\
\hline$r=\cdot / m e$ & 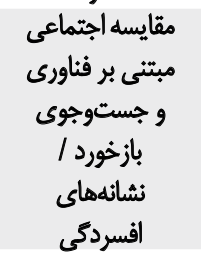 & & 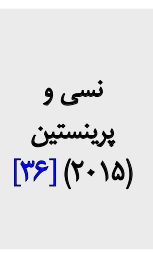 & A & $r=-/ 1 Y$ & 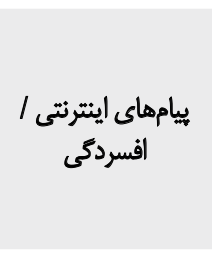 & "كوعز نفر & 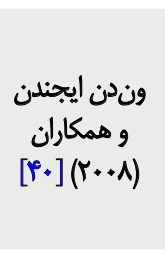 & $r$ \\
\hline$r=. / 19$ & 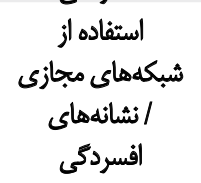 & 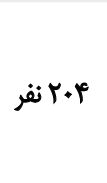 & 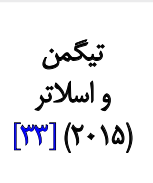 & $q$ & $r=* / / r^{w}$ & 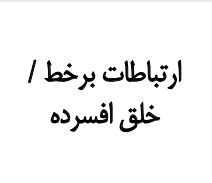 & . بوانقر & 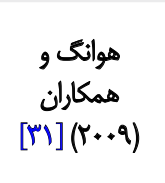 & $r$ \\
\hline $\begin{array}{c}\text { AOR:V/ब } \\
r / T) 94 \% \mathrm{Cl} \\
(1-\end{array}$ & | أفياد به فيس بوكى & جو ثقر & 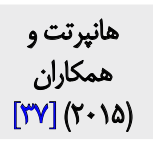 & 1. & $r=-.1 . r$ & هيامهاى برخط / أفسردى & Y.r Yنفر & 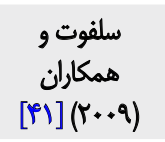 & $f$ \\
\hline$r=* / T V$ & أنشياد به اينترنت أفهائ & ع عبانقر & 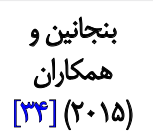 & 11 & $r=* / r$ & تشائهنيحات افسرد5ى / ترخط & 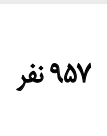 & 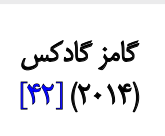 & $\Delta$ \\
\hline$r=-\cdot / 9 \mathrm{~V}$ & فيسبوك | فتفادهاز & M نفر & 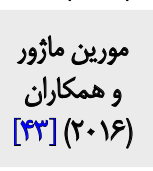 & ir & $r=-.1 .9$ & $\begin{array}{c}\text { ميزان اسثفاده از القسرده / SNS } \\
\text { خلق }\end{array}$ & 1) 19 نفر & 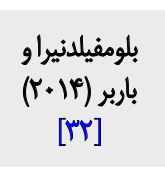 & $\varepsilon$ \\
\hline 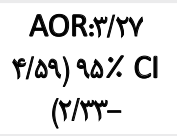 & أفازفاده از فضطاي & 1ه +ا نفر & 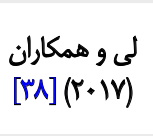 & r & $\begin{array}{c}r / T V: A O R \\
90 \% \mathrm{Cl} \\
(r / T r-r / \Delta q)\end{array}$ & 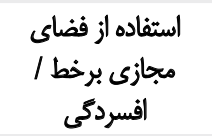 & 1ه +ا نفر & 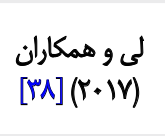 & Ir \\
\hline$r=. / T \Delta$ & 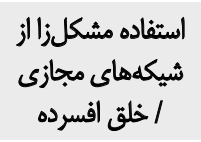 & 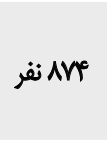 & 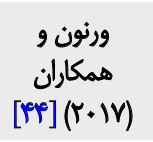 & if & $r=. / T \Delta$ & 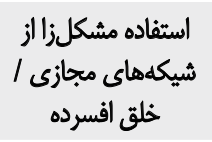 & 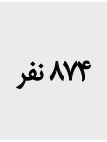 & 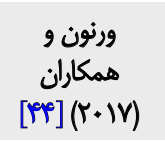 & if \\
\hline$r=* / M$ & 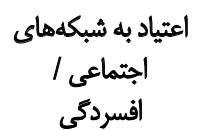 & ه ه نقر & 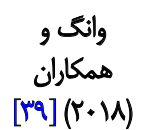 & 10 & $r=* / M A$ & 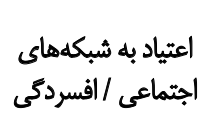 & هبr نفرّ & 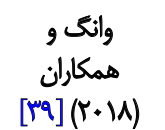 & 10 \\
\hline
\end{tabular}

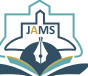

در مطالعه خود تأثير سن را نيز بررسى كردند كه در ارتباط بين

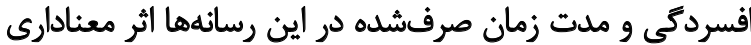

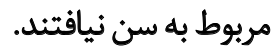

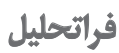

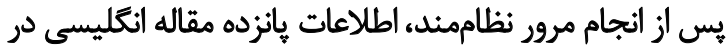

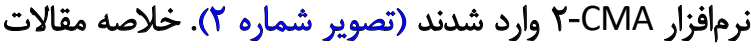

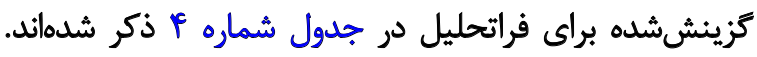

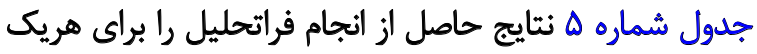

فريسون و ايكرمونت [بها] دريافتند كه استرس ميتواند

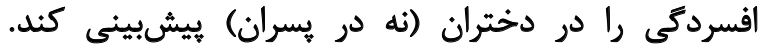

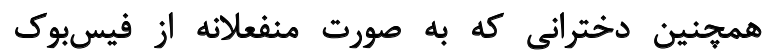

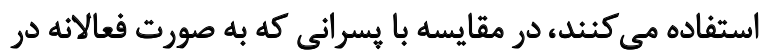

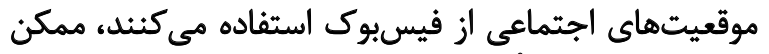

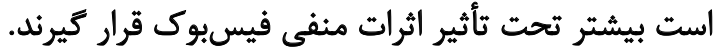
بنجانين و همكاران [FF] در بررسى ارتباط بين مدت زمان

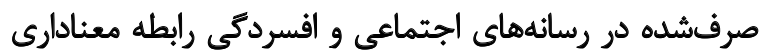
كه در ارتباط با جنسيت باشد، نيافتند. بنجانين و همكاران [TF 
جدول ه. اندازه اثر يثروششهاى واردشده به فراتحليل

\begin{tabular}{|c|c|c|c|c|c|c|c|c|c|c|c|c|c|}
\hline $\mathbf{P}$ & $\mathbf{Z}$ & حد بالال & هايين & اثدازه اثر & نو ويسندكّان & رديف & $\mathbf{P}$ & z & حد بالالا & هايين & اثدازه & نويسندكان & رديف \\
\hline $.1+.9$ & T/NTV &.$/ 1719$ & $\% \Delta F$ & .119. & 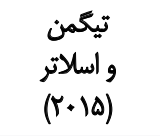 & 9 & $+\ldots$ & $\Delta / f \Delta f$ & $+/ 149$ & $1.9+$ & $+/ N F$ & 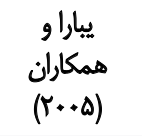 & 1 \\
\hline TH & $r /+r u$ & . TiE & $\%$ & .1111 & 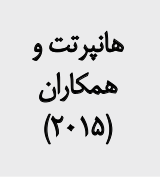 & 1. & $+\ldots$ & $f / F)$ & TH & .1 .90 & $* / / \gamma$ & ايجندن ون ونمارن & $r$ \\
\hline.$\ldots$ & $\Delta / \cdot \Delta r$ & ./Tes &.$/ 1 \& A$ & . MV & 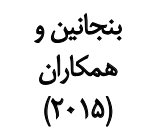 & 11 & $+\cdots$ & $1 . / m^{\circ}$ & - NAP & .11 .8 & ./r. & 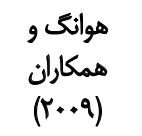 & $r$ \\
\hline 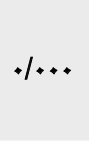 & 19/rq. &.$/ 4$ & 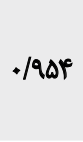 &.$/ 9 v$ & 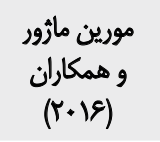 & Ir & . MTV & $\begin{array}{c}\cdot / m+q \\
-\end{array}$ & .1 .94 & $\begin{array}{c}. / 1 \pi T \\
-\end{array}$ & $\begin{array}{c}* / . r+ \\
-\end{array}$ & 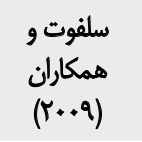 & p \\
\hline$+\ldots$ & $V /+A f$ &.$/ M M$ & A &.$/ \mu$ & $\begin{array}{c}\text { لى و همكاران } \\
\text { (r.IV) }\end{array}$ & ir & $+\ldots$ & g/TET &.$/ T E$ & ./IHA & $* / T+$. & 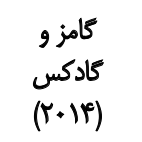 & $\Delta$ \\
\hline$\%$ & V/orA &.$/ 4 M$ & . MAV & - /ra. & $\begin{array}{l}\text { ورنون } \\
\text { وناران } \\
(Y+1 V)\end{array}$ & if & $+\ldots$ & $\begin{array}{c}\Psi / \Psi N E \\
-\end{array}$ & $-.1 \cdot+4$ & $\begin{array}{c}\text {. /rra } \\
-\end{array}$ & $\begin{array}{c}.1 .9 . \\
-\end{array}$ & بلومفيلدنيراو & 8 \\
\hline $.1 .+1$ & pher & . /TVA & .1 .89 & $.11 \mathrm{~A}$ & 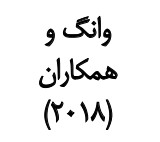 & 10 & .10 & r/qrV & ./194 & .1 .88 &.$/ \mathrm{r}$ & فريسون و ائرمونت & $v$ \\
\hline$\%$ & $\Delta / T r$. &.$/ T \Delta A$ &.$/ 189$ & . TeE & تصادفى تركيبي & & $+\ldots$ & NVM & $. / 4+1$ & ARA &.$/ \pi f$ & 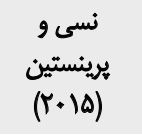 & 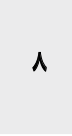 \\
\hline$+\ldots$ & WNTV &.$/ 18$ &.$/ N r$. & . NFa & اثرات ثركييى & & $1 . .48$ & T/MV &.$/ 19$ & $1+\Delta f$ &.$/ 19$ & و أيكاتمن & 9 \\
\hline
\end{tabular}

\section{$\sqrt{n}$}

مدل اثرات تصادفى، فرض مي شود اندازه اثر واقعى از يثروهشى

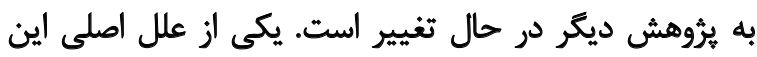

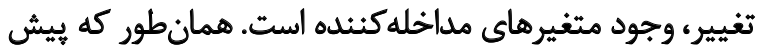

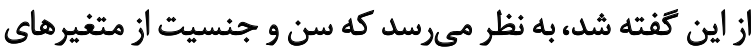

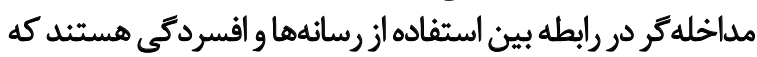

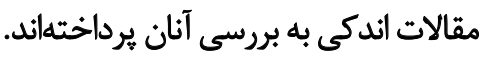
از ديكر مفروضات اصلى فراتحليل، خطاى انتشار است كه براى

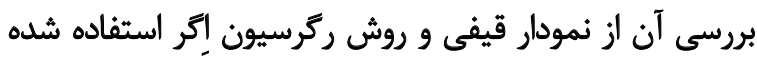

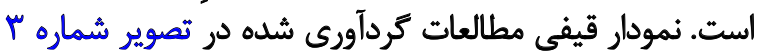

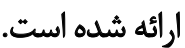

در راستاى اطمينان و بررسى بيشتر خطاى انتشار از روش
از مقالات نشان مىدهد. همانطور كه در اين جدول مشارئ إنداه

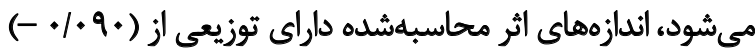

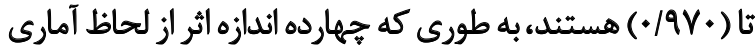

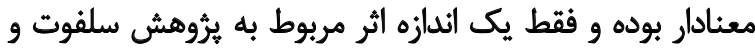

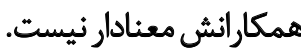
براي تعيين مدل فراتحليل، همكن بودن برؤهشها با باستفاده

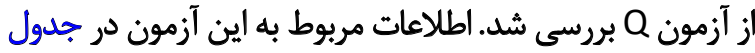

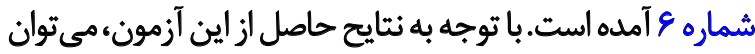

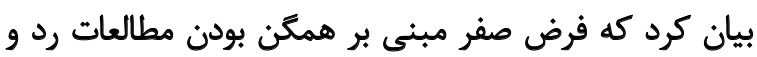

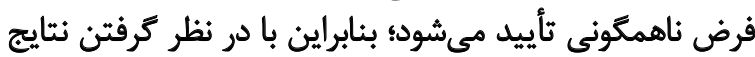

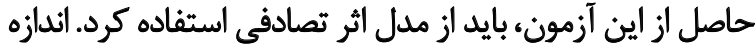

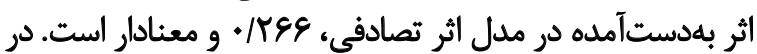




\section{Meta Analysis}

\begin{tabular}{|c|c|c|c|c|c|c|}
\hline \multirow[t]{2}{*}{ Study name } & \multirow[t]{2}{*}{ Time point } & \multicolumn{4}{|c|}{ Statistics for each study } & \multirow[b]{2}{*}{ p-Value } \\
\hline & & Correlation & $\begin{array}{c}\text { Lower } \\
\text { limit }\end{array}$ & $\begin{array}{l}\text { Upper } \\
\text { limit }\end{array}$ & Z-Value & \\
\hline Ybarra & 2005 & 0.140 & 0.090 & 0.189 & 5.454 & 0.000 \\
\hline Van den Ejden & 2008 & 0.170 & 0.095 & 0.243 & 4.410 & 0.000 \\
\hline Huang & 2009 & 0.130 & 0.106 & 0.154 & 10.375 & 0.000 \\
\hline Selfout & 2009 & -0.020 & -0.132 & 0.092 & -0.349 & 0.727 \\
\hline Gamez-Gaudx & 2014 & 0.200 & 0.138 & 0.260 & 6.262 & 0.000 \\
\hline Bomfield Neira & 2014 & -0.090 & -0.135 & -0.044 & -3.846 & 0.000 \\
\hline Frison & 2015 & 0.130 & 0.066 & 0.193 & 3.937 & 0.000 \\
\hline Nesi & 2015 & 0.340 & 0.268 & 0.408 & 8.788 & 0.000 \\
\hline Tiggemman & 2015 & 0.190 & 0.054 & 0.319 & 2727 & 0.006 \\
\hline Banjanin & 2015 & 0.270 & 0.168 & 0.366 & 5.052 & 0.000 \\
\hline Mbrin-Mbjor & 2016 & 0.970 & 0.954 & 0.980 & 19.290 & 0.000 \\
\hline Vermon & 2017 & 0.250 & 0.187 & 0.311 & 7.538 & 0.000 \\
\hline Wang & 2018 & 0.180 & 0.079 & 0.278 & 3.462 & 0.001 \\
\hline Hanprathet & 2015 & 0.111 & 0.004 & 0.216 & 2024 & 0.043 \\
\hline \multirow[t]{2}{*}{ نا } & 2017 & 0.310 & 0.228 & 0.388 & 7.084 & 0.000 \\
\hline & & 0.266 & 0.169 & 0.358 & 5.230 & 0.000 \\
\hline
\end{tabular}
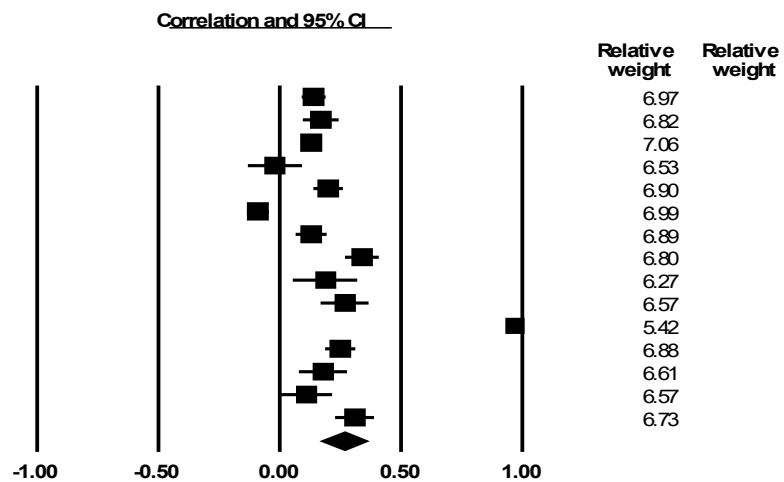

Favours A

Favours B

\section{Meta Analysis}

اثر شبكههاى اجتماعى (مدل اثرات تصادفى) بر افسردگى در

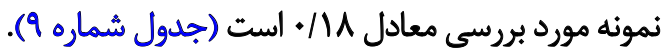

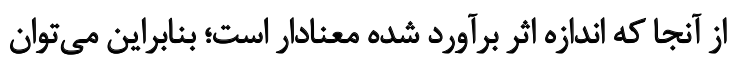

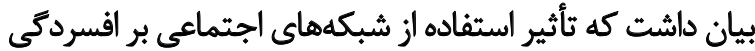

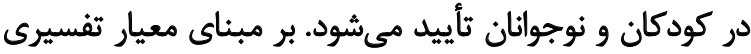

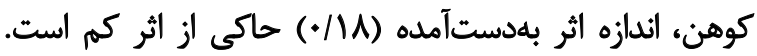

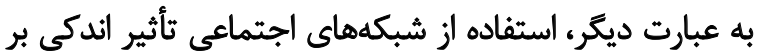

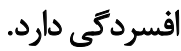

نكته ديكرى كه ذكر آن حائز اهميت است اين است كه مطالعات

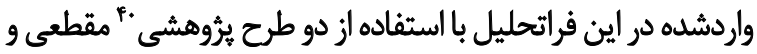

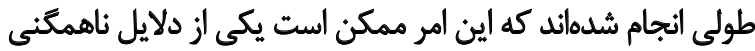

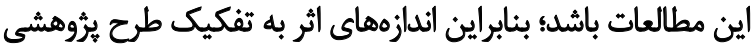

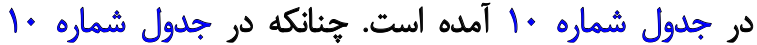

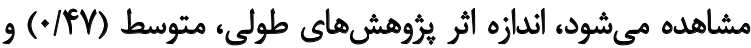

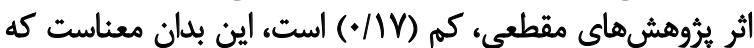

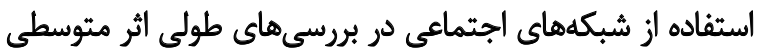

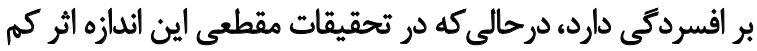

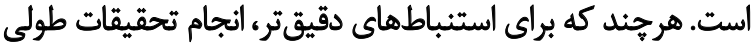

$$
\text { بيشتر ضرورى است. }
$$

40. Study design
ركرسيون اكر استفاده شد. در اين روش فرض صفرو بيانكر

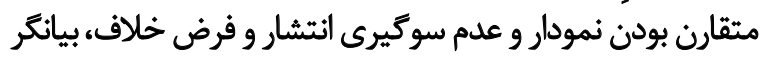

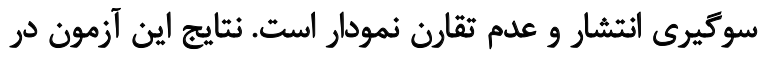
جدول شماره V بيان شده است.

سوكيرى انتشار بر اساس نمودار قيفى زمانى قابل تشخيص

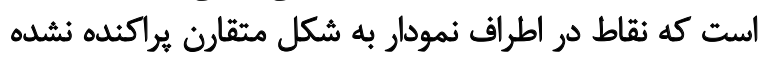
باشند و اين ناشى از مقادير بسيار بزرى اندازه انثر اثر و خطاي معيار بزرى آنها است.

با مشاهده نمودار قيفى و نتايج آزمون ركرسيون إكر مشخص

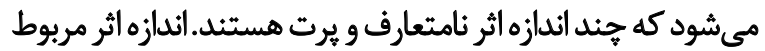

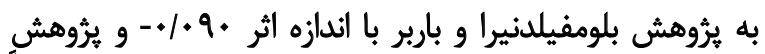

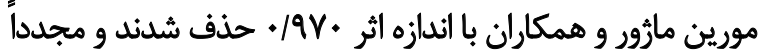

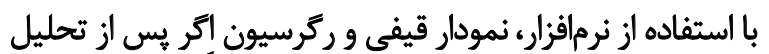

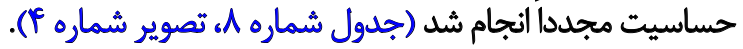
با توجه به اينكه بس از بررسى مفروضات فراتحليل اين نتيجه

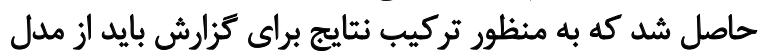

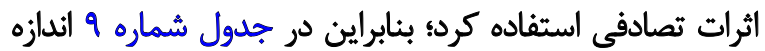

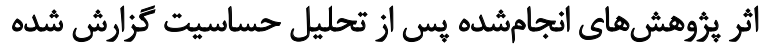
است (تصوير شماره هائ. محاسبات آمارى بيانكر اين مطلب است كه ميانگين اندازههاى

جدول و. نتايج حاصل از آزمون

\begin{tabular}{|c|c|c|c|}
\hline I - square & $\mathbf{P}$ & Df & Q مقدار آزمون \\
\hline $9 \mathrm{q} / \mathrm{/W}$ & $\%$ & if & $P q \Delta / q \Delta \mid$ \\
\hline
\end{tabular}


Funnel Plot of Standard Error by Fisher's Z

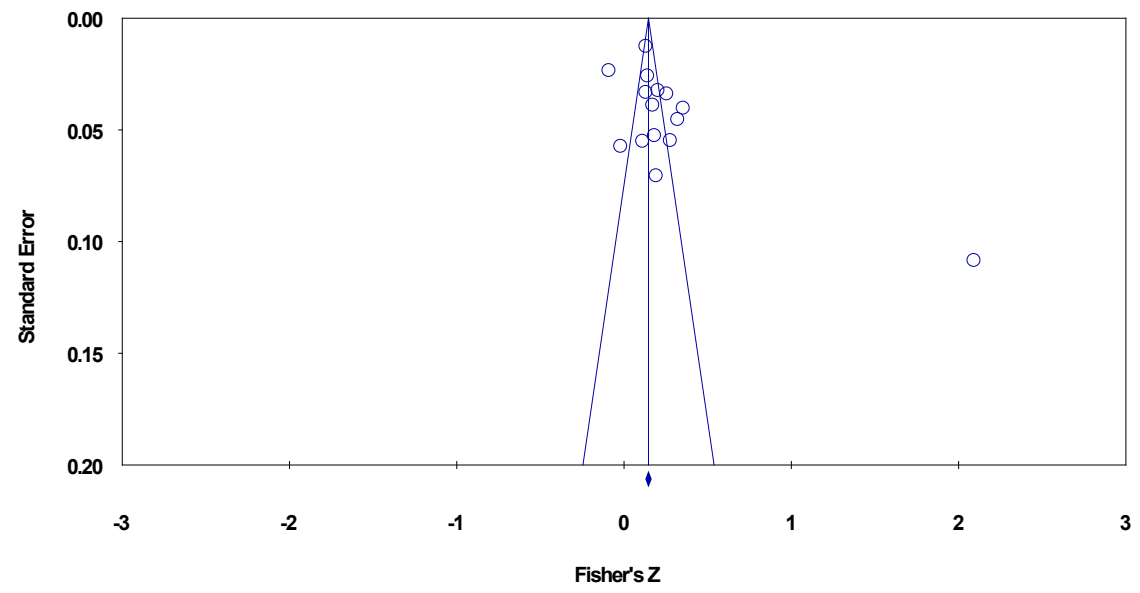

تصوير r. نمودار قيفي (Funnel plot)

بر اساس شواهدى كه از تحقيقات مقطعى (ده يثروهش)

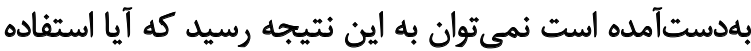

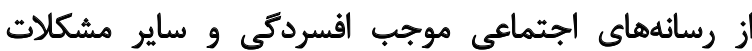

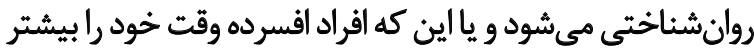

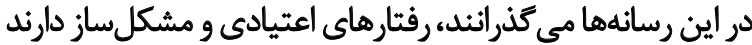
و در اين رسانهها سرمايهكذارى مى كنيند.

يافته ديكر اينكه نكرش ها يا رفتارهاى خاصى همجيون مقايسه

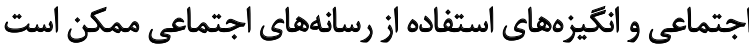

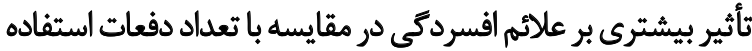

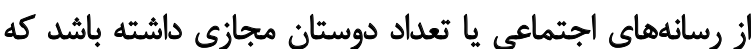

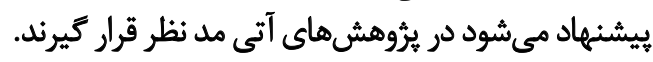

برخى از تحقيقات مورد بررسى در اين مقاله، نشان دادند كه

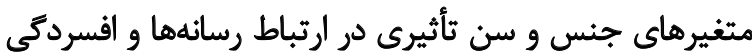

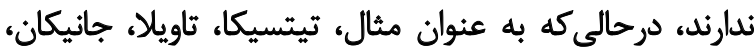

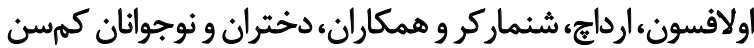

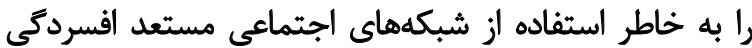

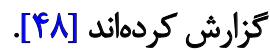

تحقيقات نشان دادهاند كه استفاده دختران از اينترنت بيشتر

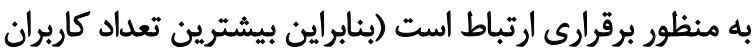

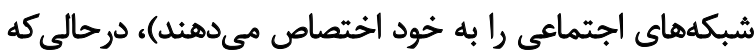

\section{بحث}

در اين مقاله سعى شد تابا بررسى و مرور تحقيقات صورت كرفته

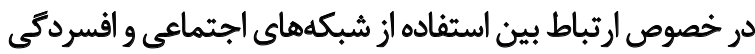

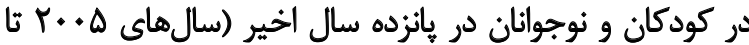

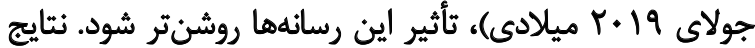

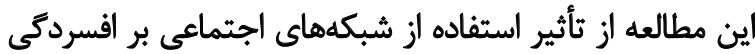

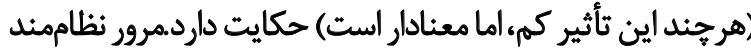

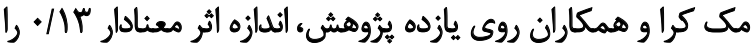

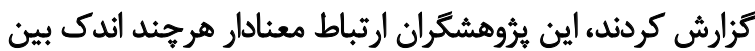

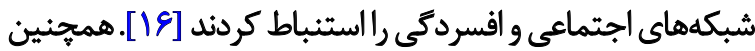

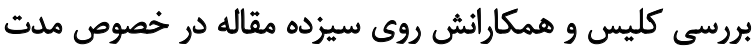

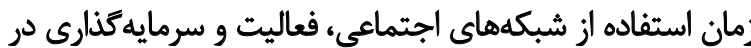

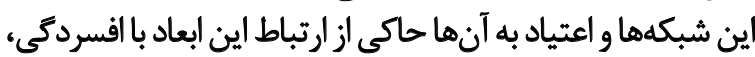

اضطراب و بريشانى روانشناختى بود [FF].

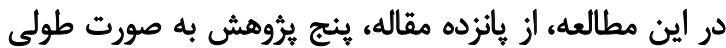

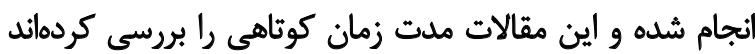

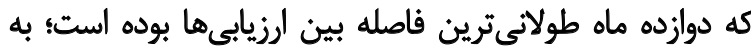

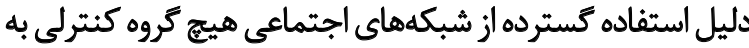

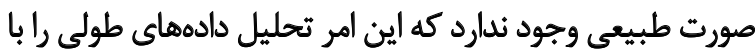

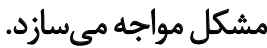

جدول V. نتايج حاصل از آزمون ركرسيون إكر

\begin{tabular}{|c|c|c|c|c|}
\hline \multicolumn{2}{|c|}{ سطح معنادارى } & \multirow{2}{*}{ t - value } & \multirow{2}{*}{ خطاى استاندارو (SE) } & \multirow{2}{*}{ برش B } \\
\hline دو دامنه & يك دامنه & & & \\
\hline 1.998 & $+/+M r A$ & V/aW & TIVNE & $P q \Delta / 9 \Delta 1$ \\
\hline
\end{tabular}


جدول ^. نتايج حاصل از آزمون ركرسيون آكر يس از تحليل حساسيت

\begin{tabular}{|c|c|c|c|c|}
\hline \multicolumn{2}{|c|}{ سطح معنى دارى } & \multirow{2}{*}{$t$ - value } & \multirow{2}{*}{ خطاي استائدارد (SE) } & \multirow{2}{*}{ برش B } \\
\hline دو دامنه & يك دامنه & & & \\
\hline.$/|r|$ & $.1 \cdot 18$ & $1 / 48$. & r/TEA & I/NAT \\
\hline
\end{tabular}

(5)

كمك هستيند [ع|] در مجموع، براي ارزيابي اثرات سن و جنس،

$$
\text { تحقيقات بيشترى لازم است. }
$$

در مجموع، جنين به نظر ميرسد كه رسانههاى اجتماعي

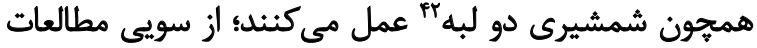

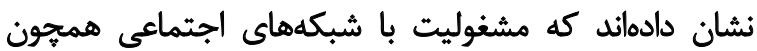

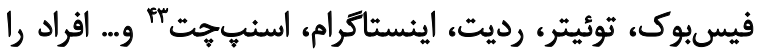

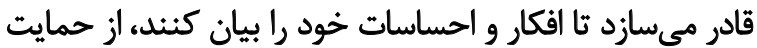

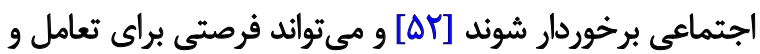

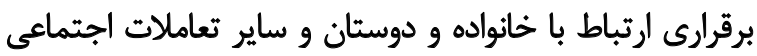
ايجاد كند.

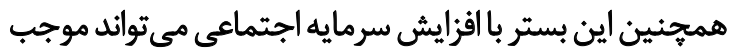

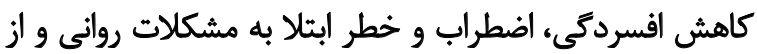

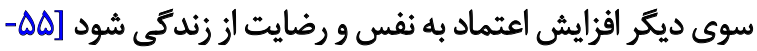

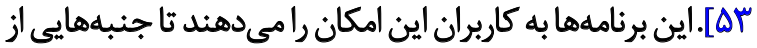

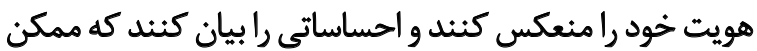

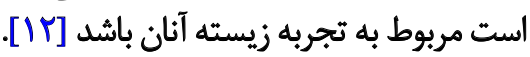

مزاياى ادراكشده "نوجوائان از شبكههاى اجتماعى ميثواند

42. Double-edged Sword

43. Facebook, Twitter, Reddit, Instagram, Snapchat

44. Perceived Benefits

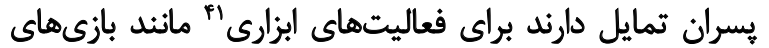

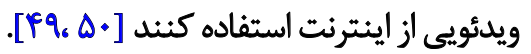

در بررسى نوجوانان كانادايى توسط سمياسا كانينيا و لوئيس

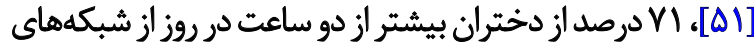

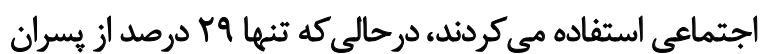
اين كونه بودند.

به نظر ميرسد كه نتايج اين تحقيق ثا حدودى مي ثواند دليل

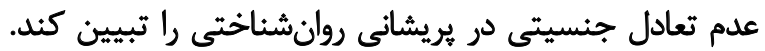

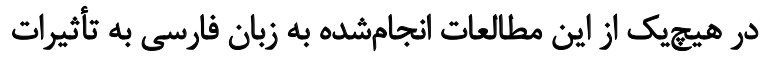

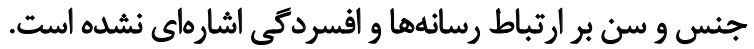
زمينهيابي كه اخيراً توسط دولت انكلستان در مورد كودكان

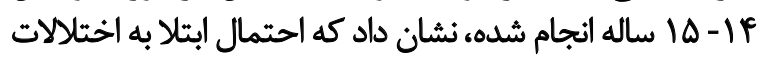

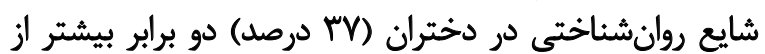

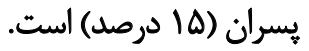
همجنين مشخص شد كه نسبت دختران مبتلا به اضطراب يا

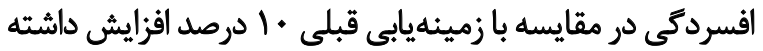

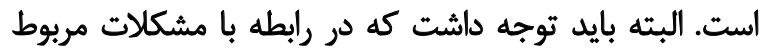

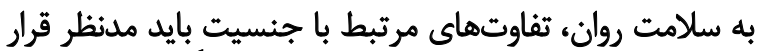

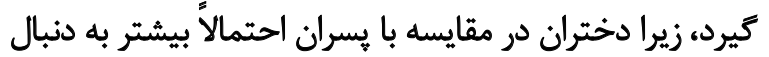

41. Instrumental Activities

Funnel Plot of Standard Error by Fisher's Z

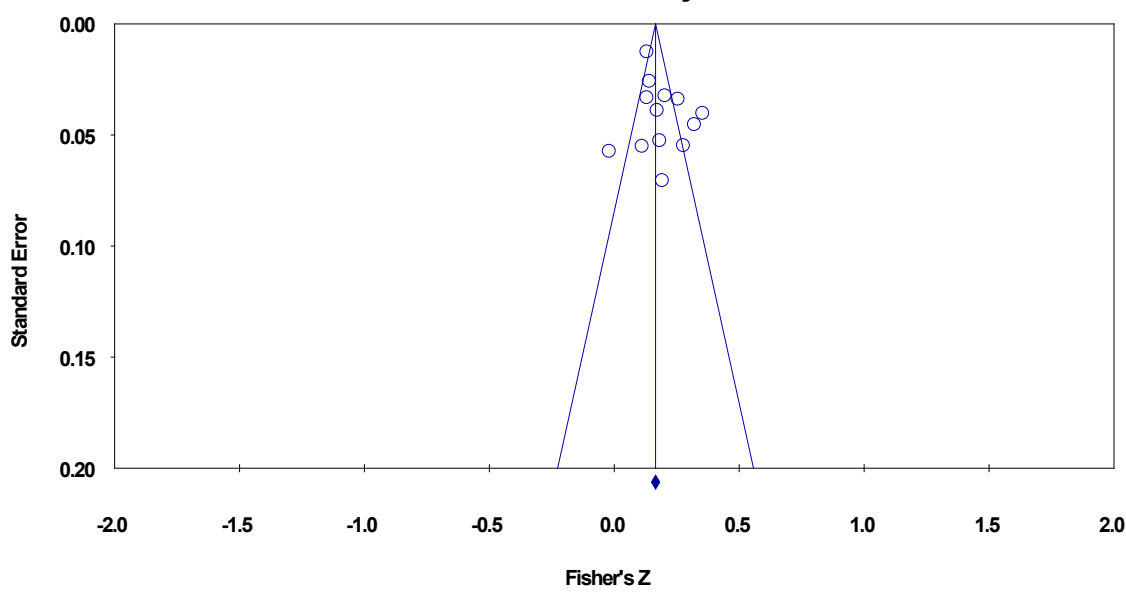

تصوير f. نمودار قيفى (Funnel plot) يس ازتحليل حساسيت 
Meta Analysis

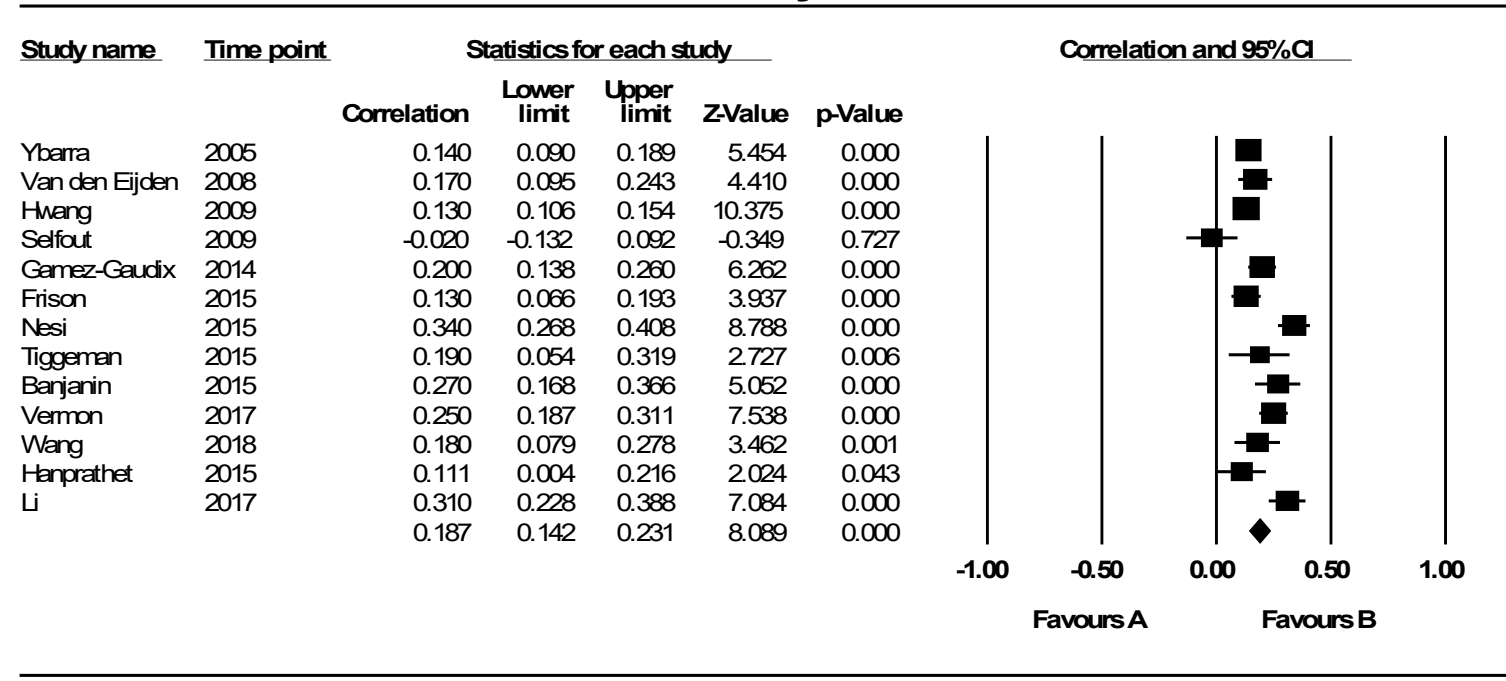

\section{Meta Analysis}

درحالي كه مي تواند فوايد آموزشى به همراه داشته باشد و زماني

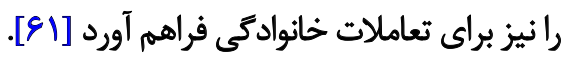

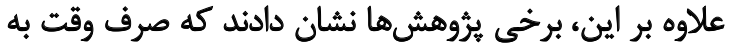

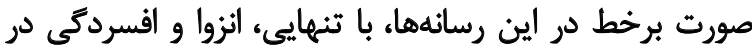

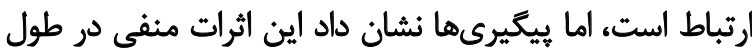

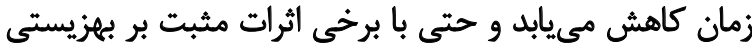
همراه است.

برخى از تحقيقاتى كه اخيراً انجام شده، ارتباط بين استفاده

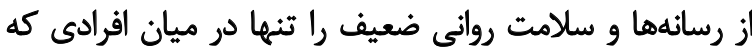

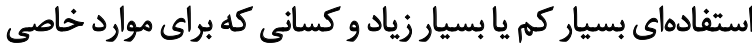

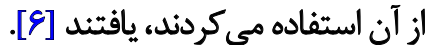

در مجموع، اين مرور نظاممند و فراتحليل ثأثير كلى استفاده إنهاه

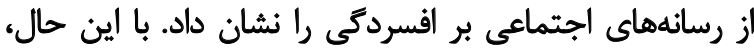

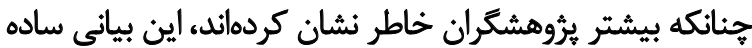

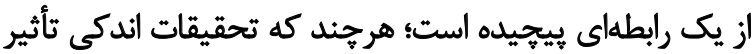
متغيرهاي تعديل كنيده يا ميانجى را مورد بررسي قرار دادهاند. متغيرهاى تعديل كنئده و ميانجى بررسى شده در مقالات شامل
شامل ارتباط بيشتر با سايرين از طريق شناسايي و تعامل با آنها

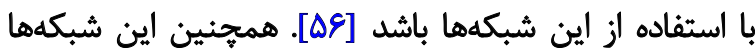

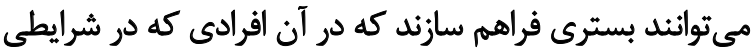

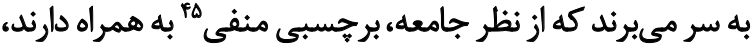

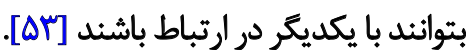

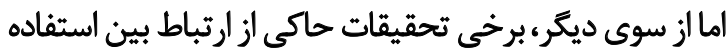

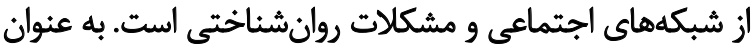

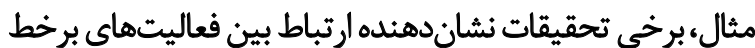

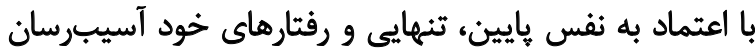
است $\left[\Delta V_{B} \Delta A\right.$ بـ

برخي يُروهشكران معتقدند كه كاهش تماس جهره بـ جههره به

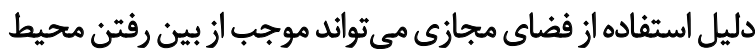

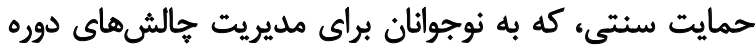

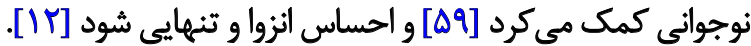
البته بايد اين نكته را در نظر داشت كه رسانههاي كوناكون

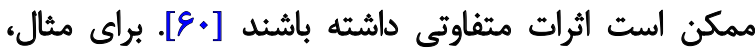

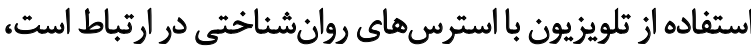

45. Stigma

جدول 9. اندازه اثر مطالعات رابطه استفاده از شبكههاي اجتماعى و افسردكى

\begin{tabular}{|c|c|c|c|c|c|}
\hline $\mathbf{P}$ & $\mathbf{Z}$ & هد بالا & هد بايين & تعداد مطالعات & اندازه اثر \\
\hline$+\ldots$ & av/iW & ./MI & - IIFT & $\pi$ & - MAV \\
\hline
\end{tabular}


جدول •1. اندازه اثر مطالعات به تفكيك طرح يروهش (مقطعى و طولى)

\begin{tabular}{|c|c|c|c|c|c|c|c|c|c|c|c|}
\hline \multicolumn{5}{|c|}{ مدل اثر ثابت } & \multicolumn{5}{|c|}{ مدل اثرات تصادفى } & \multirow{2}{*}{ مطالعات } & \multirow{2}{*}{ بروهش } \\
\hline $\mathbf{P}$ & $\mathbf{z}$ & حد بالا & حد بايين & اندازه اثر & $\mathbf{P}$ & $\mathbf{Z}$ & حد بالا & حد بايين & الثدازه اثر & & \\
\hline$\%$ & $|r| \cdot q$ &.$|1 P|$ & $\cdot / 1 \cdot V$ &.$/ 1 T r$ & $.1+$ & $f|| A \mid$ & - Mre & .1 .91 &.$/ N V$ & 1. & مقطعى \\
\hline .10. & $\mid r / \cdot V$ &.$/ m$ &.$/ T \cdot P$ & . & r.*r & r/uq & . I89 &.$/ 1 V A$ & - /4va & $\Delta$ & طولى \\
\hline
\end{tabular}

ins

راستاى اين ثروهش، بيشنهاد مىشود با توجه به تفاوتهاى

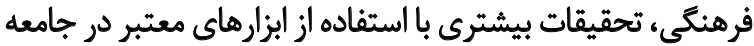
نوجوان ايرانى صورت كيرد. تئقئات بيشت

با توجه به جند عاملي بودن ارتباط شبكههاي اجتماعي و

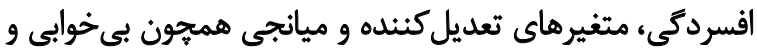

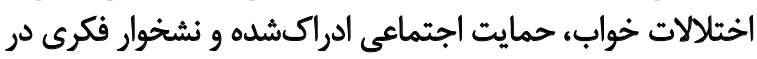
تعدادى از يثوهشها مورد بررسى قرار كرفتهاند.

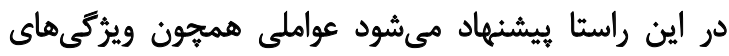

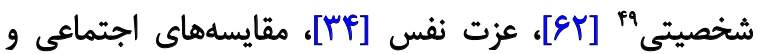

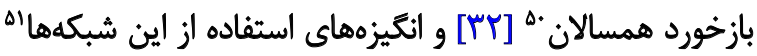

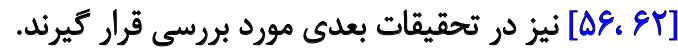

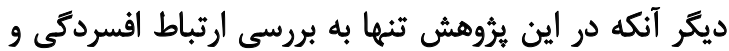

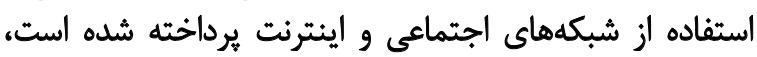

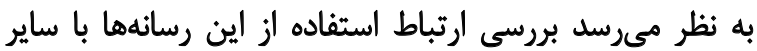

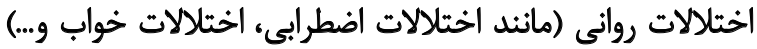

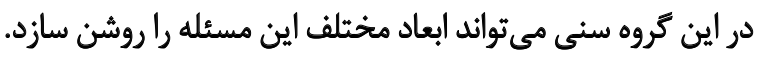
همجنين بررسى ثأثير بازى هاي بر خط بر سلامت روان نوجوانان

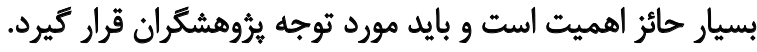

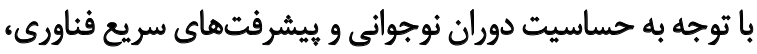

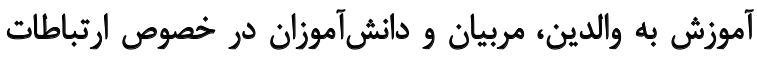
برخط و فعاليت در شبكههاى اجتماعى بايد بهروزرسانى شوند.

ملاحظاث اخلاقي

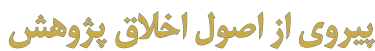

ايــن مقالـــه از نـــوع فراتحليـلـل اســت و نمونـــه انســانى و

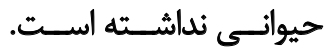

$$
\text { Ito gol }
$$

ايــن تحقيـق بــدون حمايـت مالـى سـازمان يــا نهــادى

49. Personality Traits

50. Social Comparison and Peer Feedback

51. Motivations for Social Media Use

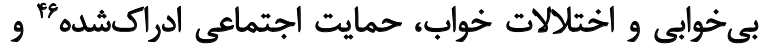

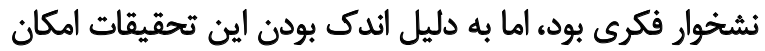

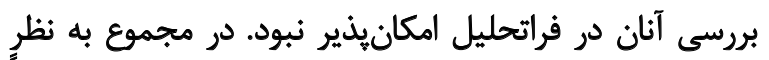

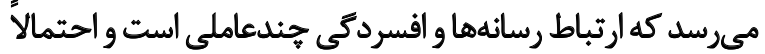
متغيرهاي مختلفى در اين ارتباط نقش ايفا مي كنئد كه بايد مورد توجه قرار كيرند.

$$
\text { S. }
$$

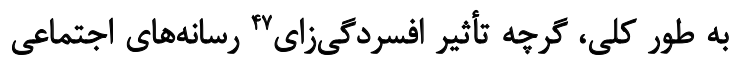

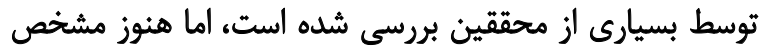

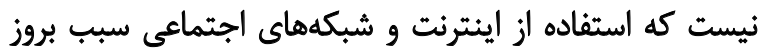

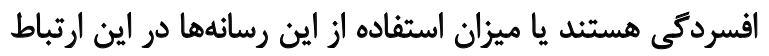

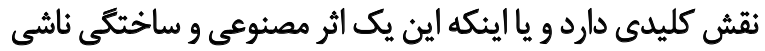
از تحقيقات موردى و نكرانى عمومى جامعه است.

به طور كلى، ميثوان اذعان داشت كه رابطه استفاده از ازئ

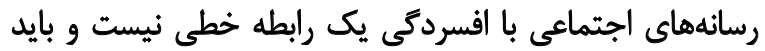
عوامل مختلف را مدنظر قرار داد.

از محدوديتهاي ثيروهش حاضر اين است كه در همه مقالات

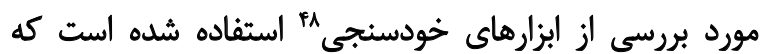

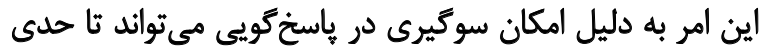

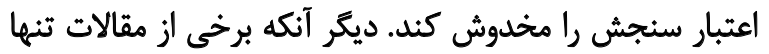

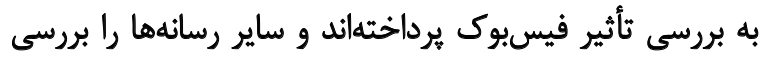

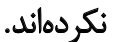

يكى ديكر از محدوديتهاى اين يثروهش، كمبود تعداد تحقيقات

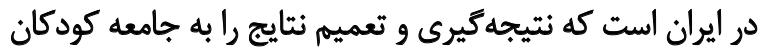
و نوجوانان ايرانى مشكل مى ائد.

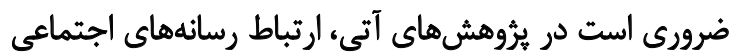

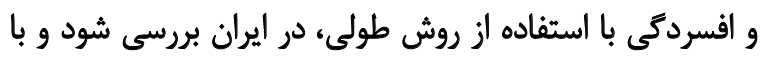

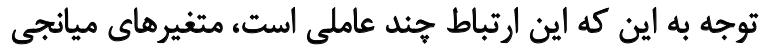
و تعديل

46. Perceived Social Support

47. Depressogenic Impact

48. Self-report 
انجــام شــده اســت.

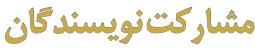

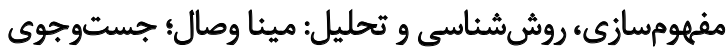

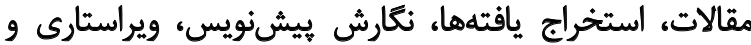

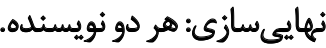

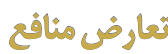

نويسندكان هيجكونه تضاد منافعى در خصوص اين بروهش نداشتند. 


\section{Reference}

[1] Ghandour RM, Sherman L, Vladutiu CJ, Ali MM, Lynch SE, Bitsko $\mathrm{RH}$, et al. Prevalence and treatment of depression, anxiety, and conduct problems in US children. J Pediatr. 2019; 206:256-67.e3. [DOI:10.1016/j.jpeds.2018.09.021] [PMID] [PMCID]

[2] Copeland WE AA, Shanahan L, Costello EJ. Longitudinal patterns of anxiety from childhood to adulthood: The great smoky mountains study. J Am Acad Child Adolesc Psychiatry. 2014; 53(1):21-33. [DOI:10.1016/j.jaac.2013.09.017] [PMID] [PMCID]

[3] Gore FM, Bloem PJN, Patton GC, Ferguson J, Joseph V, Coffey C, et al. Global burden of disease in young people aged $10-24$ years: A systematic analysis. Lancet. 2011; 377(9783):2093-102. [DOI:10.1016/ S0140-6736(11)60512-6]

[4] Thapar A, Pine DS, Leckman JF, Scott S, Snowling MJ, Taylor EA, editors. Rutter's child and adolescent psychiatry. Hoboken, New Jersey: John Wiley \& Sons; 2015. https://books.google.com/books?id=mFLKC QAAQBAJ\&printsec $=$ frontcover $\& d q=$

[5] Shensa A, Escobar-Viera CG, Sidani JE, Bowman ND, Marshal MP, Primack BA. Problematic social media use and depressive symptoms among U.S. young adults: A nationally-representative study. Soc Sci Med. 2017; 182:150-7. [DOI:10.1016/j.socscimed.2017.03.061] [PMID] [PMCID]

[6] Bickham DS, Hswen Y, Rich M. Media use and depression: Exposure, household rules, and symptoms among young adolescents in the USA. Int J Public Health. 2015; 60(2):147-55. [DOI:10.1007/s00038014-0647-6] [PMID] [PMCID]

[7] Kostev K, Teichgräber F, Konrad M, Jacob L. Association between chronic somatic conditions and depression in children and adolescents: A retrospective study of 13,326 patients. J Affect Disord. 2019, 245:697-701. [DOI:10.1016/j.jad.2018.11.014] [PMID]

[8] Barch DM, Tillman R, Kelly D, Whalen D, Gilbert K, Luby JL. Hippocampal volume and depression among young children. Psychiatry Res Neuroimaging. 2019; 288:21-8. [DOI:10.1016/j.pscychresns.2019.04.012] [PMID] [PMCID]

[9] Uchida M, Fitzgerald M, Woodworth H, Carrellas N, Kelberman C Biederman J. Subsyndromal manifestations of depression in children predict the development of major depression. J Pediatr. 2018; 201:252-8.e1. [DOI:10.1016/j.jpeds.2018.05.049] [PMID] [PMCID]

[10] Abela JR, Hankin BL. Handbook of depression in children and adolescents. New York: Guilford Press; 2008. https://psycnet.apa.org/ record/2008-01178-000

[11] Kennard BD, Hughes JL, Foxwell AA. CBT for depression in children and adolescents: $A$ guide to relapse prevention. New York: Guilford Publications; 2016. https://books.google.com/ books/about/CBT_for_Depression_in_Children_and_Adole. $\mathrm{html}$ ?id=vVq3CgAAQBAJ\&source=kp_book_description

[12] Seabrook EM, Kern ML, Rickard NS. Social networking sites, depression, and anxiety: A systematic review. JMIR Ment Health. 2016; 3(4):e50. [DOI:10.2196/mental.5842] [PMID] [PMCID]

[13] Ngai EWT, Tao SSC, Moon KKL. Social media research: Theories, constructs, and conceptual frameworks. Int J Inf Manage. 2015; 35(1):33-44. [DOI:10.1016/j.ijinfomgt.2014.09.004]

[14] Zhong B, Hardin M, Sun T. Less effortful thinking leads to more social networking? The associations between the use of social network sites and personality traits. Comput Human Behav. 2011 27(3):1265-71. [DOI:10.1016/j.chb.2011.01.008]
[15] Correa T, Hinsley AW, De Zuniga HG. Who interacts on the Web?: The intersection of users' personality and social media use. Comput Human Behav. 2010; 26(2):247-53. [DOI:10.1016/j. chb.2009.09.003]

[16] McCrae N, Gettings S, Purssell E. Social media and depressive symptoms in childhood and adolescence: A systematic review. Adolesc Res Rev. 2017; 2:315-30. [DOI:10.1007/s40894-017-0053-4]

[17] Chassiakos YLR, Radesky J, Christakis D, Moreno MA, Cross C. Children and adolescents and digital media. Pediatrics. 2016; 138(5):e20162593. [DOI:10.1542/peds.2016-2593] [PMID]

[18] Seo J-H, Kim JH, Yang KI, Hong SB. Late use of electronic media and its association with sleep, depression, and suicidality among Korean adolescents. Sleep Med. 2017; 29:76-80. [DOI:10.1016/j. sleep.2016.06.022] [PMID]

[19] Kaplan AM, Haenlein M. Users of the world, unite! The challenges and opportunities of Social Media. Bus Horiz. 2010; 53(1):59-68. [DOI:10.1016/j.bushor.2009.09.003]

[20] Carr CT, Hayes RA. Social media: Defining, developing, and divining. Atl J Commun. 2015; 23(1):46-65. [DOI:10.1080/1545687 0.2015 .972282

[21] Ventola CL. Social media and health care professionals: Benefits, risks, and best practices. P T. 2014; 39(7):491-520. [PMCID]

[22] Yoon S, Kleinman M, Mertz J, Brannick M. Is social network site usage related to depression? A meta-analysis of Facebook-depression relations. J Affect Disord. 2019; 248:65-72. [DOI:10.1016/j.jad.2019.01.026] [PMID]

[23] O'Loughlin K, Neary M, Adkins EC, Schueller SM. Reviewing the data security and privacy policies of mobile apps for depression. Internet Interv. 2019; 15:110-5. [DOI:10.1016/j.invent.2018.12.001] [PMID] [PMCID]

[24] Keles B, McCrae N, Grealish A. A systematic review: The influence of social media on depression, anxiety and psychological distress in adolescents. Int J Adolesc Youth. 2019; 25(1):79-93. [D OI:10.1080/02673843.2019.1590851]

[25] Richards D, Caldwell PH, Go H. Impact of social media on the health of children and young people. J Paediatr Child Health 2015; 51(12):1152-7. [DOI:10.1111/jpc.13023] [PMID]

[26] Internet Usage in the Middle East [Internet]. Internet World Stats. 2019. https://www.internetworldstats.com/me/ir.htm.

[27] American Academy of Pediatrics. Committee on Public Education. American academy of pediatrics: Children, adolescents, and television. Pediatrics. 2001; 107(2):423-6. [DOI:10.1542/ peds.107.2.423] [PMID]

[28] Kraut R, Patterson M, Lundmark V, Kiesler S, Mukophadhyay T, Scherlis W. Internet paradox: A social technology that reduces social involvement and psychological well-being? Am Psychol. 1998; 53(9):1017-31. [DOI:10.1037/0003-066X.53.9.1017]

[29] Young KS, Rogers RC. The relationship between depression and Internet addiction. Cyberpsychol Behav. 1998; 1(1):25-8 [DOI:10.1089/cpb.1998.1.25]

[30] Ybarra ML, Alexander C, Mitchell KJ. Depressive symptomatology, youth Internet use, and online interactions: A national survey. J Adolesc Health. 2005; 36(1):9-18. [DOI:10.1016/j.jadohealth.2003.10.012] [PMID] 
[31] Hwang JM, Cheong PH, Feeley TH. Being young and feeling blue in Taiwan: Examining adolescent depressive mood and online and offline activities. New Media Soc. 2009; 11(7):1101-21. [DOI:10.1177/1461444809341699]

[32] Blomfield Neira CJ, Barber BL. Social networking site use: Linked to adolescents' social self-concept, self-esteem, and depressed mood. Aust J Psychol. 2014; 66(1):56-64. [DOI:10.1111/ajpy.12034]

[33] Tiggemann M, Slater A. The role of self-objectification in the mental health of early adolescent girls: Predictors and consequences. J Pediatr Psychol. 2015; 40(7):704-11. [DOI:10.1093/jpepsy/jsv021] [PMID]

[34] Banjanin N, Banjanin N, Dimitrijevic I, Pantic I. Relationship between internet use and depression: Focus on physiological mood oscillations, social networking and online addictive behavior. Comput Human Behav. 2015; 43:308-12. [DOI:10.1016/j.chb.2014.11.013]

[35] Frison E, Eggermont S. The impact of daily stress on adolescents' depressed mood: The role of social support seeking through Facebook. Comput Human Behav. 2015; 44:315-25. [DOI:10.1016/j. chb.2014.11.070]

[36] Nesi J, Prinstein MJ. Using social media for social comparison and feedback-seeking: Gender and popularity moderate associations with depressive symptoms. J Abnorm Child Psychol. 2015; 43(8):1427-38. [DOI:10.1007/s10802-015-0020-0] [PMID] [PMCID]

[37] Hanprathet N, Manwong M, Khumsri J, Yingyeun R, Phanasathit M. Facebook addiction and its relationship with mental health among Thai high school students. J Med Assoc Thai. 2015; 98(S3):S81-90. [PMID]

[38] Li J-B, Lau JT, Mo PK, Su X-F, Tang J, Qin Z-G, et al. Insomnia partially mediated the association between problematic Internet use and depression among secondary school students in China. J Behav Addict. 2017; 6(4):554-63. [DOI:10.1556/2006.6.2017.085] [PMID] [PMCID]

[39] Wang P, Wang X, Wu Y, Xie X, Wang X, Zhao F, et al. Social networking sites addiction and adolescent depression: A moderated mediation model of rumination and self-esteem. Pers Individ Dif. 2018; 127:162-7. [DOI:10.1016/j.paid.2018.02.008]

[40] Van den Eijnden RJJM, Meerkerk G-J, Vermulst AA, Spijkerman $\mathrm{RCME}$, Engels RC. Online communication, compulsive Internet use, and psychosocial well-being among adolescents: A longitudinal study. Dev Psychol. 2008; 44(3):655-65. [DOI:10.1037/00121649.44.3.655] [PMID]

[41] Selfhout MHW, Branje SJT, Delsing M, ter Bogt TFM, Meeus WHJ. Different types of Internet use, depression, and social anxiety: The role of perceived friendship quality. J Adolesc. 2009; 32(4):819-33. [DOI:10.1016/j.adolescence.2008.10.011] [PMID]

[42] Gámez-Guadix M. Depressive symptoms and problematic Internet use among adolescents: Analysis of the longitudinal relationships from the cognitive-behavioral model. Cyberpsychol Behav Soc Netw 2014; 17(11):714-9. [DOI:10.1089/cyber.2014.0226] [PMID] [PMCID]

[43] Morin-Major JK, Marin M-F, Durand N, Wan N, Juster R-P, Lupien SJ. Facebook behaviors associated with diurnal cortisol in adolescents: Is befriending stressful? Psychoneuroendocrinology. 2016; 63:23846. [DOI:10.1016/j.psyneuen.2015.10.005] [PMID]

[44] Vernon L, Modecki KL, Barber BL. Tracking effects of problematic social networking on adolescent psychopathology: The mediating role of sleep disruptions. J Clin Child Adolesc Psychol. 2017; 46(2):269-83. [DOI:10.1080/15374416.2016.1188702] [PMID]
[45] Azarniad A, Sharifi G, Madani M, Khanbani M. [Mediating role of depression in the relationship between Internet addiction and sleep disorders in adolescents (Persian)]. 2nd Congress on child and adolescent psychology, 2015, Tehran. https://www.sid.ir/fa/seminar/ ViewPaper.aspx?ID=24266

[46] Beyranvand $\mathrm{H}$, Azizi A. [Study of the relationship between addiction to internet and anxiety and depression in high school students (Persian)]. $2^{\text {nd }}$ Congress on child and adolescent psychology, 2015, Iran, Tehran. https://www.sid.ir/Fa/Seminar/ViewPaper.aspx?ID=24109

[47] Shiri A, Hashemi T, MahmoodAlilo M. [Depression and signs of online addiction in students (Persian)]. Contemp Psychol. 2017; 12:1001-4. https://www.sid.ir/fa/seminar/ViewPaper.aspx?ID=92327

[48] Tsitsika AK, Tzavela EC, Janikian M, Ólafsson K, lordache A, Schoenmakers TM, et al. Online social networking in adolescence: Patterns of use in six European countries and links with psychosocial functioning. J Adolesc Health. 2014; 55(1):141-7. [DOI:10.1016/j.jadohealth.2013.11.010] [PMID]

[49] Park S. The association between Internet use and depressive symptoms among South Korean adolescents. J Spec Pediatr Nurs. 2009; 14(4):230-8. [DOI:10.1111/j.1744-6155.2009.00191.x] [PMID]

[50] Kuss DJ, Griffiths MD. Online gaming addiction in children and adolescents: A review of empirical research. J Behav Addict. 2012; 1(1):3-22. [DOI:10.1556/JBA.1.2012.1.1] [PMID]

[51] Sampasa-Kanyinga H, Lewis RF. Frequent use of social networking sites is associated with poor psychological functioning among children and adolescents. Cyberpsychol Behav Soc Netw. 2015; 18(7):380-5. [DOI:10.1089/cyber.2015.0055] [PMID]

[52] O'Keeffe GS, Clarke-Pearson K. The impact of social media on children, adolescents, and families. Pediatrics. 2011; 127(4):800-4. [DOI:10.1542/peds.2011-0054] [PMID]

[53] Primack BA, Shensa A, Escobar-Viera CG, Barrett EL, Sidani JE, Colditz JB, et al. Use of multiple social media platforms and symptoms of depression and anxiety: A nationally-representative study among U.S. young adults. Comput Human Behav. 2017; 69:1-9. [DOI:10.1016/j.chb.2016.11.013]

[54] Valkenburg PM, Peter J, Schouten AP. Friend networking sites and their relationship to adolescents' well-being and social selfesteem. Cyberpsychol Behav. 2006; 9(5):584-90. [DOI:10.1089/ cpb.2006.9.584] [PMID]

[55] Best P, Manktelow R, Taylor B. Online communication, social media and adolescent wellbeing: A systematic narrative review. Child Youth Serv Rev. 2014; 41:27-36. [DOI:10.1016/j.childyouth.2014.03.001]

[56] Barry CT, Sidoti CL, Briggs SM, Reiter SR, Lindsey RA. Adolescent social media use and mental health from adolescent and parent perspectives. J Adolesc. 2017; 61:1-11. [DOI:10.1016/j.adolescence.2017.08.005] [PMID]

[57] Lam LT, Peng Z, Mai J, Jing J. The association between internet ad diction and self-injurious behaviour among adolescents. Inj Prev. 2009; 15(6):403-8. [DOI:10.1136/ip.2009.021949] [PMID]

[58] Clayton RB, Osborne RE, Miller BK, Oberle CD. Loneliness, anxiousness, and substance use as predictors of Facebook use. Comput Human Behav. 2013; 29(3):687-93. [DOI:10.1016/j.chb.2012.12.002]

[59] Oldmeadow JA, Quinn S, Kowert R. Attachment style, social skills, and Facebook use amongst adults. Comput Human Behav. 2013; 29(3):1142-9. [DOI:10.1016/j.chb.2012.10.006] 
[60] Mundy LK, Canterford L, Olds T, Allen NB, Patton GC. The association between electronic media and emotional and behavioral problems in late childhood. Acad Pediatr. 2017; 17(6):620-4. [DOI:10.1016/j.acap.2016.12.014] [PMID]

[61] Page AS, Cooper AR, Griew P, Jago R. Children's screen viewing is related to psychological difficulties irrespective of physical activity. Pediatrics. 2010; 126(5):e1011-7. [DOI:10.1542/peds.2010-1154] [PMID]

[62] O'Dea B, Campbell A. Online social networking amongst teens: Friend or foe? In: Wiederhold BK, Riva G, Bouchard S, editors. Annual Review of Cybertherapy and Telemedicine 2011. $1^{\text {th }}$ ed. Amsterdam: IOS Press; 2011. [DOI:10.3233/978-1-60750-766-6-133] 